\title{
LAS EMISIONES DE GASES DE EFECTO INVERNADERO EN EL SECTOR TRANSPORTE POR CARRETERA
}

\author{
José Antonio Sotelo Navalpotro, María Sotelo Pérez, \\ Alfredo Tolón Becerra \\ Grupo de Investigación: «Desarrollo y Gestión Ambiental del Territorio» (IUCA/UCM) \\ Universidad Complutense. Madrid
}

\section{RESUMEN}

La investigación que presentamos parte de la idea de que el transporte por carretera en sus modalidades, mercancías y pasajeros, y este último en sus dos tipos, privado y público conforma un sector con una notable relevancia socioeconómica. De hecho hay estimaciones que fijan su aportación al PIB de España en un $7 \%$ como media, alcanzando un 10\% si se incluye el transporte por cuenta propia, y la producción de los medios y de las infraestructuras de transporte. Así, a los evidentes beneficios que aporta a la economía, que en gran medida se ven reflejados en las pertinentes estadísticas, habría que detraerle los notables costes que implica no sólo en términos de aumentar la dependencia energética de nuestro país, el enorme y dramático coste derivado de la accidentalidad, y también el derivado de los problemas que ocasiona en materia de contaminación y uso del suelo y congestión de las infraestructuras. En él se sientan las bases metodológicas para la construcción, por fases, de un Sistema de Indicadores que permita la evaluación y el seguimiento de la sostenibilidad del sector del Transporte en su triple dimensión: económica, ambiental y social; la comparación sincrónica y diacrónica de los indicadores; el establecimiento de valores Umbrales: críticos y deseables, y de valores Objetivos de progresos realistas hacia los deseables.

Palabras clave: Emisiones GEI, $\mathrm{CO}_{2}$, transporte por carretera, España, diferencias regionales. 


\begin{abstract}
The research presented on the idea that the road transport modalities, goods and passengers, and the latter in two types, private and public sector makes up a considerable socioeconomic relevance. In fact some estimates set its contribution to GDP of Spain by 7\% on average, reaching 10\% if one includes the own-account transport, and media production and transport infrastructure. Thus, the obvious benefits of the economy, which largely reflected in the relevant statistics, should be deducted from the outstanding costs involved not only in terms of increasing energy dependence of our country, the huge and dramatic cost resulting from accidents, and the derivative of the problems caused in terms of pollution and land use and infrastructure congestion. It lays the methodological foundations for construction in phases, a system of indicators to allow assessment and monitoring of the sustainability of transport sector in three dimesions: economic, environmental and social comparison synchronic and diachronic indicators, the establishment of threshold values: critical and desirable values and objectives realistic progress toward desirable.
\end{abstract}

Keywords: GHG Emissions, $\mathrm{CO}_{2}$, trucking, Spain, regional differences.

\title{
1. INTRODUCCIÓN
}

A lo largo de las últimas décadas trabajos como los del profesor Francisco Higón, han puesto de manifiesto que el transporte por carretera causaba algo más de la cuarta parte de las emisiones de $\mathrm{CO}_{2}$. Además las cifras del sector transporte muestran notable crecimiento, un 1,9\%anual en el caso del transporte de pasajeros y hasta un $2,7 \%$ en el de mercancías, cifras que rebasan las mejoras en la eficiencia energética experimentada por los diferentes modos de transporte. A nivel nacional, en el 2008, España ocupaba el décimo lugar en la Europa de los quince en relación a la antigüedad del parque de turismos con más de 10 años. Además para que tengamos una referencia diremos que, según fuentes de la DGT, el Parque Nacional de vehículos a 31 de diciembre de 2009 estaba compuesto por casi 31 millones de vehículos, de los cuales los turismos representaban un 71,51\% (algo más de 23 millones de vehículos), pero es que además el parque de vehículos crece de un modo que parece incontenible (en el año 2009 se incrementó en un 2,46 \% con respecto a 2008).

El sector del transporte en España tiene una importante repercusión socioeconómica, tanto directa como indirecta, sobre otras actividades económicas, productivas y de consumo. Es una actividad estratégica para sectores 
básicos en la economía como la industria, el comercio o el turismo, que, sin su participación no podrían disponer de materias primas adecuadas, dar salida a sus productos, o recibir a sus clientes. Y es que el consumo de energía de los vehículos privados representa en España alrededor del 50\% del total de los consumos del transporte por carretera. El porcentaje restante corresponde fundamentalmente al tráfico de mercancías (alrededor del 47\%), y, con una participación mínima, al transporte colectivo de pasajeros (un 3\%); el desarrollo social y económico ha propiciado un gran aumento de la movilidad de las personas (número de kilómetros recorridos por viajero). En el año 2009, el transporte (carretera, ferrocarril, marítimo, aéreo) absorbió en España cerca del $40 \%$ del consumo final de energía. En el mismo año, la carretera representó el $80 \%$ del total de consumos del transporte. El transporte precisa actuaciones que permitan mejorar la eficiencia energética y suavizar de forma significativa sus consumos. El consumo de energía de los vehículos privados representa en España alrededor del 50\% del total de los consumos del transporte por carretera. El porcentaje restante corresponde fundamentalmente al tráfico de mercancías (alrededor del 47\%), y, con una participación mínima, al transporte colectivo de pasajeros (un 3\%). El desarrollo social y económico ha propiciado un gran aumento de la movilidad de las personas (número de kilómetros recorridos por viajero). En el conjunto de las ciudades españolas se realizan aproximadamente un número igual de viajes en coche privado y en transporte público. El uso del coche está centrado principalmente en recorridos cortos: cerca de la mitad de los recorridos en coche en España son de $6 \mathrm{~km}$ o menos.

Según los datos publicados para el 2009, se han emitido 367.600 miles de toneladas de gases de efecto invernadero, un 8,2\% menos que en 2008. La tendencia a la baja de las emisiones de los dos últimos años ha permitido aproximarse a los índices de referencia del 115\% establecido en el Protocolo de Kioto. Los datos de emisiones de 2009 sitúan a España en un 128,5\%, mientras que en 2008 los índices de emisiones fueron del 140\%. Para el periodo 2008-2012, la previsión del Gobierno español es alcanzar los 137\% de media de emisiones de $\mathrm{CO}_{2}$ totales y cumplir así los objetivos de Kioto. Según la secretaria de Estado, la tendencia de disminución de emisiones de gases de efecto invernadero en España se ha mantenido además en el primer cuatrimestre de 2010. Durante este periodo la generación de electricidad ha crecido un $5 \%$, mientras que las emisiones han caído un $20 \%$, debido a la disminución del uso del carbón, la situación meteorológica (aumento de las precipitaciones) y el aumento de la energía eólica. Sin embargo, a pesar del cambio «tan sustancial» en la producción de energía, la caída de emisiones puede 
no mantenerse durante los próximos años. Cuando se recupere la actividad industrial, «es difícil pensar que se produzcan las caídas de los últimos años». Pero un perfil de crecimiento junto a una disminución de las emisiones demuestra que una electricidad limpia es "posible», sobre todo propiciada por el incremento del $12 \%$ de las energías renovables y un descenso «muy significativo» de las fuentes fósiles (una bajada del 24,3\% en el carbón, un 6,6\% en el petróleo, y un 10,6\% en el gas natural).

Las principales caídas de emisiones de gases de efecto invernadero se han producido en el ámbito de la energía (electricidad, transporte y procesos industriales), y han tenido «mucho que ver» con el sector de la construcción. En 2009 las emisiones de $\mathrm{CO}_{2}$ debidas a la generación de electricidad disminuyeron un $15,3 \%$ con respecto a 2008. Las emisiones de combustión industrial bajaron un $9,9 \%$ (los procesos industriales sin combustión lo han hecho un $21,7 \%)$. En cuanto al transporte por carretera, las emisiones de $\mathrm{CO}_{2}$ descendieron por segundo año consecutivo, en 2009 un 5,8\% (en otros modos de transporte, la disminución ha sido del 3,5\%). No obstante, las emisiones han aumentado un $18,5 \%$ en el uso de disolventes y otros productos (sobre todo, sustancias de la anestesia y otros productos farmacéuticos), aunque en términos absolutos «sólo» representan el 2,4\% del total de las emisiones. Las emisiones también han aumentado en el tratamiento y eliminación de residuos (un 3,5\%), que representan el 4,7\% de las emisiones totales. En la agricultura, no ha habido casi variación de emisiones de 2008 a 2009.

Así, pues, nadie pone en duda la relevancia socioeconómica del transporte por carretera, si bien con un coste importante en lo que a la contaminación atmosférica en las ciudades se refiere (Gurjar et al., 2008, Colvile et al., 2002) y sus efectos sobre la salud humana (Curtis et al., 2006). El sector en España no es ajeno a esta situación, y según el Inventario Nacional de Emisiones a la Atmósfera (MMA, 2010), en 2009 las emisiones del transporte por carretera supusieron el 26\% de las partículas de diámetro aerodinámico inferior a 2,5 micras $(\mathrm{PM} 2,5)$ y el $27 \%$ del $\mathrm{CO}_{2}$ respecto al total generado en España. Mayor fue su contribución a la emisión de otros contaminantes como los óxidos de nitrógeno (NOX, 34\%), el monóxido de carbono (CO, 40\%) y el cobre ( $\mathrm{Cu}$, $69 \%$ ). En algunos contaminantes la emisión del transporte por carretera ha experimentado un fuerte crecimiento desde finales del siglo pasado, como en el caso del dióxido de carbono, cuya generación se ha incrementado un $85 \%$ en el periodo 1990-2009. Estos valores confirman la trascendencia del transporte por carretera a la hora de diseñar políticas que conduzcan de manera efectiva, desde un punto de vista del análisis coste-beneficio, en la reducción 
de contaminantes atmosféricos a nivel nacional (tal y como podemos observar y valorar en la siguiente tabla).

Tabla 1. Factores que influyen en las emisiones atmosféricas del transporte por carretera

\begin{tabular}{|c|c|c|}
\hline ÁMBITO & FACTORES & INDICADORES \\
\hline \multirow{4}{*}{$\begin{array}{l}\text { Viajeros y } \\
\text { mercancías }\end{array}$} & Movilidad de viajeros & $\begin{array}{l}\text { Distancia anual recorrida por el } \\
\text { conjunto de viajeros en turismos, } \\
\text { autobuses, motocicletas y } \\
\text { ciclomotores (viajeros por } \mathrm{km} \text { ) }\end{array}$ \\
\hline & Movilidad de mercancías & $\begin{array}{l}\text { Distancia anual recorrida por } \\
\text { el conjunto de mercancías } \\
\text { transportadas en vehículos ligeros } \\
\text { y pesados (toneladas por km) }\end{array}$ \\
\hline & $\begin{array}{l}\text { Ocupación de vehículos de } \\
\text { pasajeros }\end{array}$ & $\begin{array}{l}\text { Factor de ocupación: número } \\
\text { medio de viajeros por cada tipo de } \\
\text { vehículo (viajeros/vehículo) }\end{array}$ \\
\hline & $\begin{array}{l}\text { Carga de vehículos de } \\
\text { mercancías }\end{array}$ & $\begin{array}{l}\text { Factor de carga: peso medio } \\
\text { de la mercancía transportada } \\
\text { (toneladas/vehículo) }\end{array}$ \\
\hline \multirow[t]{2}{*}{$\begin{array}{l}\text { Uso de } \\
\text { combustibles }\end{array}$} & $\begin{array}{l}\text { Distribución de combustibles } \\
\text { por tipo de vehículo }\end{array}$ & $\begin{array}{l}\text { Contribución de cada } \\
\text { combustible (gasolina, diesel, } \\
\text { gases licuados del petróleo, gas } \\
\text { natural, hidrógeno, electricidad) } \\
\text { en el recorrido de cada tipo de } \\
\text { vehículo (\%) }\end{array}$ \\
\hline & Consumo de combustible & $\begin{array}{l}\text { Consumo por unidad de distancia } \\
\text { recorrida (litros/100 km) por tipo } \\
\text { de vehículo }\end{array}$ \\
\hline \multirow{4}{*}{$\begin{array}{l}\text { Modos de } \\
\text { conducción }\end{array}$} & $\begin{array}{l}\text { Distribución de recorridos por } \\
\text { pauta }\end{array}$ & $\begin{array}{l}\text { Porcentaje del recorrido efectuado } \\
\text { en pauta interurbana, rural y } \\
\text { urbana }(\%)\end{array}$ \\
\hline & $\begin{array}{l}\text { Velocidad media de los } \\
\text { vehículos }\end{array}$ & $\begin{array}{l}\text { Distancia recorrida por unidad de } \\
\text { tiempo }(\mathrm{km} / \mathrm{h})\end{array}$ \\
\hline & Eficiencia de conducción & $\begin{array}{l}\text { Disminución del consumo } \\
\text { respecto a condiciones estándar } \\
\text { de conducción del vehículo (\%) }\end{array}$ \\
\hline & $\begin{array}{l}\text { Frecuencia de uso y distancia } \\
\text { media recorrida por trayecto }\end{array}$ & $\begin{array}{l}\text { Recorrido medio por vehículo } \\
(\mathrm{km} / \mathrm{año}) \text {. Distancia media por } \\
\text { trayecto }(\mathrm{km})\end{array}$ \\
\hline
\end{tabular}




\begin{tabular}{|c|l|l|}
\hline \multirow{5}{*}{ Vehículos } & Edad del parque de vehículos & $\begin{array}{l}\text { Número de vehículos por año de } \\
\text { matriculación (vehículos o \%) }\end{array}$ \\
\cline { 2 - 3 } & $\begin{array}{l}\text { Cilindrada y carga bruta de los } \\
\text { vehículos }\end{array}$ & $\begin{array}{l}\text { Distribución de vehículos } \\
\text { por cilindrada y carga bruta } \\
\text { (vehículos o \%) }\end{array}$ \\
\cline { 2 - 3 } & Vida útil de los vehículos & $\begin{array}{l}\text { Curvas de vida de los vehículos: } \\
\text { porcentaje de vehículos que } \\
\text { sobreviven cada alo respecto a su } \\
\text { fecha de matriculación (\%) }\end{array}$ \\
\cline { 2 - 3 } & $\begin{array}{l}\text { Reducción de la distancia } \\
\text { recorrida con la edad del } \\
\text { vehículo }\end{array}$ & $\begin{array}{l}\text { Factor de reducción del } \\
\text { kilometraje con la edad (\%) }\end{array}$ \\
\hline \multirow{2}{*}{ Tecnologías } & $\begin{array}{l}\text { Penetración de nuevas } \\
\text { tecnologías en el parque nuevo } \\
\text { de vehículos de cada año }\end{array}$ & $\begin{array}{l}\text { Contribución al parque nuevo de } \\
\text { cada tecnología (\%) }\end{array}$ \\
\hline
\end{tabular}

Fuente: Lumbreras, J. et alii. (2006). «Metodología para la cuantificación de medidas de reducción de emisiones de contaminantes atmosféricos en el transporte por carretera». Madrid.

\section{OBJETIVOS Y METODOLOGÍA}

Los objetivos del presente trabajo, expresados en forma resumida, buscar conocer la realidad inherente a las emisiones de gases de efecto invernadero en el sector transporte por carretera, en España, así como valorar las diferencias territoriales generadas, deteniéndonos en los aspectos siguientes:

- Localizar, clasificar y analizar la información disponible relativa a la situación española.

- Localizar y analizar la información disponible a nivel internacional.

- Desarrollar y poner en práctica nuevas metodologías, que coadyuven a un mejor conocimiento de la mencionada realidad.

- Extraer conclusiones acerca de la situación española en los aspectos más relevantes.

- Ofrecer conclusiones y recomendaciones.

Para ello, hemos empleado una metodología (Tolón, A. y Lastra, J) para el cálculo de los coeficientes de reducción ponderados de las correspondientes emisiones, por Comunidades Autónomas, de Gases de Efecto Invernadero, a partir de dos funciones de distribución logarítmica inversa, que toman como punto de referencia la tasa inicial del año 1990 (año base, recogido en el Protocolo de Kioto con el objetivo de reducción de emisiones de GEI, para las emisiones de $\mathrm{CO}_{2}, \mathrm{CH}_{4}$ y $\mathrm{N}_{2} \mathrm{O}$ ), para los valores de las Emisiones de Gases de 
Efecto Invernadero con respecto del Producto Interior Bruto (PIB) y respecto a la población total, de cada una de las Comunidades Autónomas.

Desglosando la formulación matemática de dichas funciones logarítmicas, hemos denominado con los siguientes valores a las correspondientes variables: en cada Comunidad Autónoma (i), en un año (t), la tasa de emisión de Gases Efecto Invernadero, en toneladas de $\mathrm{CO}_{2}$ equivalente (GHG), dividida por el Producto Interior Bruto en ese año concreto (t), expresado en millones de euros (GDP).

$$
E(G D P)_{i, t}=\frac{G H G_{i, t}}{G D P_{i, t}}\left(\mathrm{tCO}_{2} \mathrm{EQ} / \text { millones } €\right),
$$

De igual modo, hemos calculado en cada Comunidad Autónoma (i), en un año $(\mathrm{t})$, las emisiones de Gases Efecto Invernadero en toneladas de $\mathrm{CO}_{2}$ equivalente (GHG), dividida por el total de la población al principio de cada año, relacionada por habitantes $(\mathrm{P})$.

$$
E(\ln h .)_{i, t}=\frac{G H G_{i, t}}{P_{i, t}}\left(\mathrm{tCO}_{2} \mathrm{EQ} / \text { habitante }\right)
$$

Dicha formulación, atendiendo a la tasa inicial de las emisiones del transporte por carretera en España por Comunidades Autónomas, pretende analizar de manera concisa la vinculación real existente entre la contaminación y el propio cambio climático; mientras que la función logarítmica inversa se adapta a los objetivos de obtención de coeficientes modulados de reducción, relacionando los mayores niveles de reducción de emisiones de efecto invernadero del transporte por carretera, en aquellas zonas en las que la problemática de contaminación es mayor.

De igual modo, para el cálculo de emisiones de los factores de emisión y de las emisiones de de $\mathrm{CO}_{2}, \mathrm{CH}_{4}$ y $\mathrm{N}_{2} \mathrm{O}$, se ha tomado como base la metodología del proyecto CORINE-AIRE, del informe técnico de la Agencia Europea de Medio Ambiente ( COPERT IV Computer Programme to Calculate Emissions from Road Transport»). La fórmula para el cálculo de las emisiones finales de $\mathrm{CO}_{2}$ del transporte por carretera queda de la siguiente manera:

$$
E_{f, \mathrm{CO}_{2}}^{F}=44,011 \frac{Q_{f}}{12,011+1,008 r_{H / C}+16,000 r_{O / C}}
$$

Los valores totales calculados $\left(E_{f, \mathrm{CO}_{2}}^{F}\right)$ son las emisiones finales de $\mathrm{CO}_{2}$ producidas por el consumo de carburante $f$; el consumo total de carburante viene representado por $\left(Q_{f}\right)$; y las otras variables que configuran la fórmula matemática, son la relación entre el número de átomos de hidrógeno y carbono 
del carburante $\left(r_{H / C}\right)$ y la relación entre el número de átomos de oxigeno y carbono en el carburante $\left(r_{O / C}\right)$.

De igual modo, con el fin de lograr los objetivos del Protocolo de Kioto de reducir las emisiones de $\mathrm{CO}_{2}$ del transporte, en un 8\% desde 2008 hasta 2012 tomando como referencia el año $1990\left(\mathrm{GHG}_{\mathrm{i}, 2012}=\mathrm{c}^{* *} \mathrm{GHG}_{\mathrm{i}, 1990}\right.$; «c'» es el coeficiente residual total complementario del coeficiente de reducción), se ha tomado como referencia la siguiente base matemática (Tolón, A. et aliis):

$$
a=\frac{G H G_{2012}}{\sum_{i=1}^{n}\left(G H G_{i, 1990} / \ln E_{i, 1990}\right)}=\frac{c^{*} G H G_{1990}}{\sum_{i=1}^{n}\left(G H G_{i, 1990} / \ln E_{i, 1990}\right)}
$$

Donde se ha utilizado una función de distribución logarítmica inversa para calcular el coeficiente residual ( $\left.c^{\prime}\right)$ de cada Comunidad Autónoma (i), en función de su tasa inicial de emisión $\left(\mathrm{E}_{\mathrm{i}}\right), c^{\prime}{ }_{i}=f\left(E_{i, 1990}\right)=a\left(\ln E_{i, 1990}\right)^{-1}$; donde $(a)$ es el factor que modula el coeficiente de ponderación $\left(c^{\prime}{ }_{i}\right), G H G_{i, 2012}=\left(a\left(\ln E_{i, 1900}\right)^{-1}\right) G H G_{i, 1990}$; y GHG es la suma de las cantidades de las emisiones de cada Comunidad Autónoma, $G H G_{2012}=\sum_{i=1}^{n} \frac{a^{*} G H G_{i, 1990}}{\ln E_{i, 1990}}$.

El principal problema de la investigación se encuentra en la necesidad de homogeneizar la formulación matemática a los propios datos de estudio de cada una de las Comunidades de Autónomas, cuestión fundamental ya que la «homogeneidad» es el requisito principal para poder realizar comparaciones interregionales (tanto en variables tales como la emisión de gases contaminantes por parte del transporte por carretera, como en el conjunto global de las bases de datos utilizadas). El conjunto de datos y valores de las correspondientes «Emisiones de Gases Efecto Invernadero» en el ámbito territorial español utilizados en el análisis en nuestro estudio se publican periódicamente por el «Departamento General para la Evaluación de la Calidad Ambiental» (DGECA), si bien, se han empleado a la par datos de la Confederación Sindical de Comisiones Obreras (CCOO); por su parte, los referentes a la población y al Producto Interior Bruto (PIB), por Comunidades Autónomas, los hemos obtenido del Instituto Nacional de Estadística (INE).

El análisis temporal llevado a cabo toma como referencia el periodo 19902009, incluyéndose las Ciudades Autónomas de Ceuta y Melilla. 


\section{RESULTADOS}

\subsection{Emisiones de Gases Efecto Invernadero en España:}

A partir de la aplicación de la metodología señalada, las emisiones de Gases de Efecto Invernadero, en general, y del transporte por carretera, en particular han evolucionado de manera desigual y con un incremento o reducción de valores muy heterogéneo en las regiones españolas. El crecimiento económico y la expansión de la población han sido algunos de los factores clave en esta evolución desigual entre las distintas Comunidades Autónomas ya que, aquellas en las que se ha incrementado los ingresos (y, por ende, los gastos) tanto privados como públicos (mayores prestaciones sociales, ayudas públicas, subsidios, ...), ha producido nuevas necesidades vinculadas al transporte privado con lo que se ha tendido a invertir más en el «parque automovilístico»-sobre todo de vehículos diesel-, lo que ha incentivado los desplazamientos tanto en corta como larga distancia. Tal y cómo nos muestra la tabla 1, los vehículos con motor diesel ascendieron a 14.660.448 unidades (10.135.488 son automóviles), superando a los de gasolina (14.612.697 vehículos, de los cuales 11.624.686 son automóviles) incrementándose respecto a años anteriores, con lo que aumentaron considerablemente las emisiones en el año 2007 respecto a años anteriores puesto que el consumo de los vehículos diesel (11,7/100 km) es muy superior a los de motor de gasolina $(9,5 / 100 \mathrm{~km})$. De igual modo, el aumento de la población ha ejercido mayor presión en el territorio, sobre todo, en aquellas zonas en las que se ha producido un «crecimiento urbanístico insostenible», que hace indispensable el uso continuo del vehículo privado para cualquier cuestión vital. Las nuevas necesidades de movilidad (número de kilómetros recorridos por viajeros) por motivos de ocio, trabajo, familia, turismo,..., han producido un efecto contrario del deseado y estipulado en el Protocolo de Kioto.

Tabla 1. Tráfico, flota y consumo de combustible por tipo de transporte y tipo de combustible, España 2007

\begin{tabular}{|l|c|r|r|r|r|r|r|}
\hline $\begin{array}{c}\text { Tipo de } \\
\text { transporte }\end{array}$ & $\begin{array}{c}\text { Tráfico } \\
\text { interurbano } \\
\left(10^{6} \text { veh-km }\right)\end{array}$ & $\begin{array}{c}\text { Flota Total } \\
\text { (vehículos })\end{array}$ & Interurbano & $\begin{array}{c}\text { Consumo } \\
\text { Urbano } \\
\left(10^{6} \text { litres }\right)\end{array}$ & Total & $\begin{array}{c}\text { Consumo } \\
\text { medio } \\
(\mathbf{1} / 100 \mathrm{~km})\end{array}$ \\
\hline Motor a gasolina \\
\hline Motocicletas & 1751 & 2311346 & 113 & 61 & 174 & 6.4 \\
\hline Furgones & 7317 & 676665 & 999 & 250 & 1248 & 13.5 \\
\hline Automóviles & 55912 & 11624686 & 5251 & 1481 & 6732 & 9.2 \\
\hline Total & 64980 & 14612697 & 6363 & 1795 & 8158 & 9.5 \\
\hline
\end{tabular}




\begin{tabular}{|l|r|r|r|r|r|r|}
\hline Motor a Diesel & \multicolumn{7}{|l|}{$\mid$} & \\
\hline Camiones & 35510 & 2765919 & 10548 & 673 & 11221 & 29.5 \\
\hline Buses & 1660 & 61039 & 467 & 64 & 530 & 28.0 \\
\hline Furgones & 19020 & 1759041 & 2249 & 750 & 2999 & 11.7 \\
\hline Automóviles & 135566 & 10135488 & 9642 & 4967 & 14609 & 7.0 \\
\hline Total & 191756 & 14660448 & 22906 & 6454 & 29366 & 11.7 \\
\hline
\end{tabular}

Fuente: Ministerio de Fomento, Ministerio de Economía y Ministerio del Interior (2008).

De hecho, el incremento del Parque Nacional de Vehículos en el año 2009 fue muy elevado, teniendo en cuenta la tendencia anual de compra de nuevos vehículos (tabla 2), hasta totalizar las 30.855 .969 unidades, totalizando el $71,25 \%$, el parque de turismos. Esta renovación del parque automovilístico ha favorecido que los incrementos porcentuales de emisiones de estas últimas décadas sean inferiores a los que habría habido de no ser por dicha renovación, ya que con las nuevas legislaciones se ha tendido a modernizar los automóviles con el fin de reducir las emisiones, amén de hacer controles de inspecciones técnicas regulares de los nuevos vehículos.

Tabla 2: Parque Nacional de Vehículos, año 2009

\begin{tabular}{|l|c|c|}
\hline \multicolumn{1}{|c|}{ Tipo de vehículos } & Parque a 31/12/2009 & \% sobre el total \\
\hline Camiones y furgonetas & 5.136 .214 & $16,65 \%$ \\
\hline Autobuses & 62.663 & $0,20 \%$ \\
\hline Turismos & 21.983 .485 & $71,25 \%$ \\
\hline Motocicletas & 2.606 .674 & $8,45 \%$ \\
\hline Tractores industriales & 206.730 & $0,67 \%$ \\
\hline Otros vehículos & 860.203 & $2,79 \%$ \\
\hline TOTAL & 30.855 .969 & $100,00 \%$ \\
\hline
\end{tabular}

Fuente: Dirección General de Tráfico (DGT). 2010.

Por otro lado, cabe destacar, que estos aumentos progresivos de emisiones de Gases Efecto Invernadero provienen, en su mayoría, del transporte por carretera, y están relacionados con la implantación de distintas políticas y programas de reducción de emisiones de $\mathrm{CO}_{2}$. Los clásicos «impuestos Pigouvianos» que exponían la tesis de "quién contamina, paga», han dado paso a nuevas estrategias de penalización (impuestos de matriculación, controles de emisión en las ITV,...), alcanzando gran importancia la fiscalidad que grava al sector del transporte por carretera (ya que el principio de desafectación 
impositiva que hace que los impuestos no sean finalistas, no hacen factible la creación de fondos especiales para la financiación de las infraestructuras del transporte, acondicionadas para reducir las emisiones de GEI). No debemos olvidarnos que en los momentos presentes uno de los objetivos prioritarios de las políticas de transporte es alcanzar los objetivos del Protocolo de Kioto de reducir en 2012 las emisiones de $\mathrm{CO}_{2}$ en un 8\%, y, así progresivamente hasta el año 2020, con el fin de hacer frente al cambio climático.

De esta forma, para llegar a los valores deseables, atendiendo a la heterogeneidad del propio territorio y las distintas necesidades de la población, deben adoptarse decisiones descentralizadas en los distintos niveles territoriales. Si entramos en el análisis de los resultados (gráfico 1), vemos cómo el aumento de las emisiones del transporte por carretera ha sido muy rápido, pasando de las 50.000 miles de toneladas en el año 1990 hasta las 300.000 miles de toneladas en el año 2009. Podemos relacionar este incremento progresivo de las emisiones de GEI con el ya citado aumento del Parque Nacional de Vehículos, que está vinculado, en primera instancia, con el crecimiento económico del país, que ha favorecido la mejora en la calidad de vida de la población por el aumento de su poder adquisitivo, coadyuvando a alcanzar una mayor movilidad de la población por cuestiones de ocio (desplazamientos durante fines de semana), vivienda-trabajo (movimientos pendulares por la residencia de la población en el extrarradio de las ciudades o en zonas rururbanas, movimientos pendulares centro-periferia), consumo (en grandes centros comerciales),...

\section{Gráfico 1}

\section{EVOLUCIÓN DE LAS EMISIONES DEL TRANSPORTE POR CARRETERA}

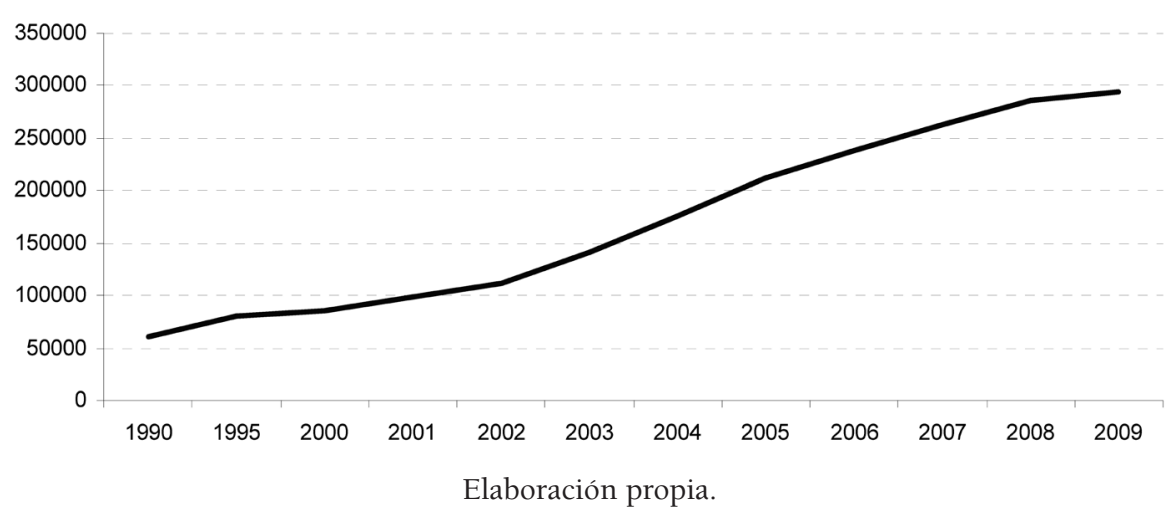

Investigaciones geográficas, $n^{\circ} 54$ (2011) 
Gráfico 2

EYOLUCIÓN DE LAS EMISIONES DELTRAN SPORTE POR CARRETERAEN COMPARACIÓN CON ELTOTALDELASEMISIONES

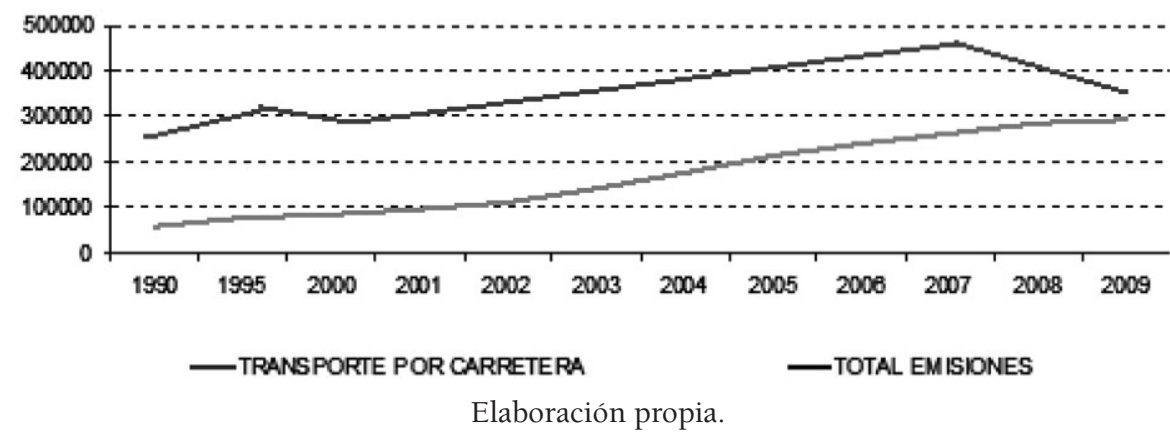

Si establecemos una comparativa entre las emisiones de Gases de Efecto Invernadero del transporte por carretera y el total de las emisiones de GEI (Gases Efecto Invernadero) en España, podemos observar cómo se da una tendencia alcista de manera progresiva, a lo largo de todo el periodo estudiado, pasando de unas 280.000 miles de toneladas de $\mathrm{CO}_{2}$ emitidas en el año 1990 hasta alcanzar los 370.000 miles de toneladas de $\mathrm{CO}_{2}$ en el año 2009 (gráficos 1 y 2). De igual modo, afirmar que el peso total de las emisiones de $\mathrm{CO}_{2}$ del transporte por carretera respecto del total de emisiones en España, es muy importante. Cabe destacar que, al dar comienzo, la crisis económica en España, la tendencia alcista de las últimas décadas toca techo y comienza a descender, aunque de manera poco brusca, desde las 440.000 miles de toneladas en el año 2007 hasta las 370.000 miles de toneladas en el año 2009 (pese a todo, no debemos olvidar que en los Gases Efecto Invernadero, el $\mathrm{CO}_{2}$ presentan emisiones que triplican los valores recomendados en el Protocolo de Kioto).

En cuanto a la caída en los últimos dos años del periodo estudiado (20082009) podemos afirmar que tienen una estrecha vinculación con el sector energético y el propio ámbito de la energía (transporte, procesos industriales y electricidad, aunque este último es el sector que más a reducido sus emisiones como consecuencia de las nuevas fuentes de energía renovable -eólica y solar- ya que evitan la emisión de GEI, reduciendo sus costes de producción, por su baja elasticidad-precio de la demanda compensada, la falta de competencia en el mercado mundial, la internalización de los costes de producción 
y por la inexistencia de bienes sustitutivos.) y, por ende, relación con la caída del sector de la construcción. En 2009, las emisiones del transporte cayeron, aproximadamente, un 5,5\% (a excepción de las emisiones del transporte por carretera que continuaron incrementándose) mientras que en los procesos industriales con combustión descendieron casi un 10\%, siendo superados por la generación de electricidad que disminuyó un 15\% (si bien, dichas disminuciones no han tenido un impacto tan notable como cabría esperar, ya que se ha sido compensado por el incremento de las emisiones de las actividades de eliminación de residuos en un 4\%, más la producción de disolventes y otros productos farmacéuticos, en casi un 19\%).

Tabla 3. Evolución de las emisiones por tipo de gases:

Valores absolutos ( $\mathrm{Gq} \mathrm{CO}$ equivalente)

\begin{tabular}{|c|r|r|r|r|r|r|r|r|}
\hline GAS & \multicolumn{1}{c|}{1990} & \multicolumn{1}{c|}{1995} & \multicolumn{1}{c|}{2000} & \multicolumn{1}{c|}{2005} & \multicolumn{1}{c|}{2006} & \multicolumn{1}{c|}{2007} & \multicolumn{1}{c|}{2008} & \multicolumn{1}{c|}{2009} \\
\hline $\mathrm{CO}_{2}$ & $225.815,08$ & $253.703,72$ & $304.708,65$ & $364.222,05$ & $354.914,23$ & $364.383,42$ & $334.702,82$ & $296.942,31$ \\
\hline $\mathrm{CH} 4$ & $26.318,28$ & $29.093,12$ & $33.546,61$ & $35.346,65$ & $35.833,26$ & $36.573,93$ & $36.062,22$ & $63.387,22$ \\
\hline $\mathrm{N} 2 \mathrm{O}$ & $27.681,80$ & $26.456,13$ & $32.317,69$ & $28.295,68$ & $28.651,61$ & $29.205,42$ & $26.256,71$ & $26.209,49$ \\
\hline $\mathrm{HFC}$ & $2.403,18$ & $4.645,44$ & $8.349,46$ & $5.423,30$ & $6.005,67$ & $6.328,97$ & $7.079,85$ & $7.361,15$ \\
\hline PFC & 882,92 & 832,51 & 436,03 & 288,17 & 294,17 & 298,18 & 314,85 & 297,28 \\
\hline SF6 & 66,92 & 108,34 & 204,60 & 271,63 & 323,62 & 339,97 & 354,07 & 350,98 \\
\hline $\begin{array}{l}\text { TOTAL } \\
\text { GASES }\end{array}$ & & & & & & & & \\
\hline
\end{tabular}

Fuente: Inventario de GEI de España (1990-2009), 2009.

Al estudiar los diferentes tipos de gases (tabla 3) cabe destacar que el dioxido de carbono es el principal emitido a la atmósfera, con una ponderación en torno al $80 \%$ a lo largo del periodo inventariado (un 79,7\% de 1990 y llegando hasta $80,8 \%$ en el año 2009). Tras el dióxido de carbono encontramos el metano y el óxido nitroso con un peso relativamente similar, aunque destacándose el metano un poco por encima, presentando una evolución desde el 9,3\% al 9,9\% en el caso del metano y el óxido nitroso del 9,9\% al 7,1\% entre el año 1990 y el 2009. De igual modo sucede en las emisiones de GEI por parte del transporte por carretera, en el que los gases representativos de estas emisiones a la atmósfera son el dióxido de carbono $\left(\mathrm{CO}_{2}\right)$ el cual ha ido en aumento, prácticamente, duplicando los valores de 1990, el metano $\left(\mathrm{NH}_{4}\right)$ que ha visto reducido el total de sus emisiones en un porcentaje considerable en las últimas dos décadas) y óxido nitroso $\left(\mathrm{N}_{2} \mathrm{O}\right)$ que apenas ha experimentado un ligero aumento. 
Tabla 4. Evolución de las emisiones del transporte por carretera, por tipo de gases: Valores absolutos ( $\mathrm{Gq} \mathrm{CO}_{2}$ equivalente)

\begin{tabular}{|c|r|r|r|r|r|r|r|r|}
\hline GAS & \multicolumn{1}{c|}{1990} & \multicolumn{1}{c|}{1995} & \multicolumn{1}{c|}{2000} & \multicolumn{1}{c|}{2005} & \multicolumn{1}{c|}{2006} & \multicolumn{1}{c|}{2007} & \multicolumn{1}{c|}{2008} & \multicolumn{1}{c|}{2009} \\
\hline $\mathrm{CO}_{2}$ & 50.442 & 60.341 & 76.899 & 91.940 & 94.802 & 97.540 & 92.311 & 86.114 \\
\hline $\mathrm{CH} 4$ & 14,71 & 14,58 & 11,61 & 7,96 & 6,86 & 6,27 & 5,32 & 4,90 \\
\hline $\mathrm{N} 2 \mathrm{O}$ & 1,59 & 2,43 & 4,36 & 2,80 & 2,86 & 2,94 & 2,86 & 2,64 \\
\hline
\end{tabular}

Fuente: Inventario de GEI de España (1990-2009), 2009.

El conjunto de los gases fluorados se muestra con un rango de participación comprendida entre 1,1\% (año 1991) y 2,4\% (año 2000) a lo largo del periodo inventariado. Al comparar las tres partes de la tabla 4 , se puede apreciar cómo el $\mathrm{CO}_{2}$ incrementa su participación relativa en 1,0 puntos porcentuales al comparar el año 1990 con el año 2009, año que a su vez se sitúa un 2,0\% por debajo de la media del último quinquenio. En contraste, puede observarse una variación pequeña para el $\mathrm{CH} 4$, con un rango de oscilación entre los extremos de aquellos cortes temporales del $0,6 \%$, pues su horquilla para dichos periodos varía desde el 9,3\% del año 1990 al 9,9\% de 2009. El N $\mathrm{N}_{2} \mathrm{O}$ refleja una mayor caída porcentual que el CH4, pasando del 9,8\% en el año 1990 a un $7,1 \%$ en 2009 , con un intermedio de $6,7 \%$ en el último quinquenio. En cuanto a los gases fluorados, se observan diferencias entre sus componentes (HFC, PFC y SF6), pero en conjunto su participación aumenta hasta el año 2000, al que sigue una pauta de descenso y una recuperación posterior en los últimos años, situándose en $2,2 \%$ en 2009 , y en $1,7 \%$ para la media de los últimos cinco años. En todo caso, los gases fluorados han mantenido a lo largo del período de estudio un nivel bajo de contribución a las emisiones totales entre 1990 y 2009.

Cabe destacar, que durante todo el periodo de estudio, las centrales termoeléctricas del carbón (Santamaría, J. et alii) son responsables de aproximadamente el 16\% de las emisiones totales de Gases Efecto Invernadero en el año 2007, como consecuencia del bajo precio de producción de $\mathrm{CO}_{2}$. Pero esta circunstancia dio un giro en el año 2008, como consecuencia del aumento del precio del $\mathrm{CO}_{2}$ y porque se duplicó el precio del carbón importado. Aunque, como ya se ha comentado anteriormente, el sector eléctrico ha sido el que más a favorecido la reducción de las emisiones, continúa siendo uno de los sectores principales más contaminantes.

El sector de la construcción y todas las industrias ligadas a este -tales como las fábricas de cemento, de ladrillos, de uralita, de metal...- son responsables de un porcentaje importante de las emisiones de GEI. Pero tras la 
«crisis del ladrillo» se ha incurrido en una disminución de la producción de las mismas, manifestando un fiel reflejo de ello en el pequeño pero importante disminución en los dos últimos años de las emisiones de $\mathrm{CO}_{2}$. Aunque en inicio fue un leve retroceso que se ha ido incrementando progresivamente en los años siguientes 2010-2011.

$\mathrm{Y}$ es que, es por todos conocido que las emisiones de $\mathrm{CO}_{2}$ han ido en aumento a lo largo de las últimas décadas. Si descendemos al análisis de las diferentes Comunidades Autónomas españolas, encontramos que una de las Comunidades más relevantes en el estudio es la Comunidad Autónoma de Castilla y León que ha presentado niveles de emisiones muy altos (tercera posición tras Cataluña y Andalucía) pero que ha ido reduciendo progresivamente el total de sus emisiones de $\mathrm{CO}_{2}$ equivalentes, desde las 34.787 miles de toneladas en 1990 hasta los 31.326 miles de toneladas en 2009. De igual modo, ocurre en Asturias que ha ido reduciendo sus emisiones totales desde 27.445 miles de toneladas en 1990 hasta los 22.238 miles de toneladas en 2009. Mientras que el resto de las Comunidades Autónomas han ido incrementando progresivamente sus emisiones totales de $\mathrm{CO}_{2}$. Cabe destacar como índice interesante los valores absolutos de la Comunidad de Madrid, puesto que, siendo una ciudad-capital cosmopolita, muy poblada, gran soporte económico en términos macroeconómicos, con mucho movimiento de vehículos diariamente,... son muy bajos (el peso total de las emisiones de GEI, como veremos más adelante, recae fundamentalmente en el transporte) como consecuencia de que el grueso de su economía de fundamenta en el sector servicio, incluido el sector turístico y es menos intensivo que en décadas pasadas, en emisiones en el sector secundario o industrial. Al igual que Madrid -apenas han aumentado las emisiones en 10.000 miles de toneladas desde 1990-, otras Comunidades Autónomas como las Islas Baleares, las Islas Canarias, Cantabria, Navarra, Murcia y las Ciudades Autónomas de Ceuta y Melilla, han incrementado sus emisiones de $\mathrm{CO}_{2}$ de manera progresiva pero sin superar las 5.000 miles de toneladas. Aunque este aumento de las emisiones de $\mathrm{CO}_{2}$ no ha sido equilibrado a lo largo de todos los años, ya que en el año 2.000 las emisiones se redujeron en la mayor parte de las Comunidades Autónomas (manifiesto de la renovación del parque automovilístico que produjo grandes beneficios tanto desde el punto de vista de la seguridad como del impacto ambiental), emitiendo 29.7483 miles de toneladas en toda España en el año 2.000 frente a las 31.4840 miles de toneladas emitidas en 1.995. Andalucía redujo sus emisiones respecto al año 1995 en 12.464 miles de toneladas, Aragón en 895 miles de toneladas, Asturias minoró sus emisiones en 4.370 miles de toneladas, la Comunidad Autónoma de Cantabria las 
redujo en 463 miles de toneladas, Castilla y León disminuyó sus emisiones en 1.076 miles de toneladas, Galicia redujo sus emisiones en 1.264 miles de toneladas casi como el País Vasco que las minoró en 1.182 miles de toneladas. El resto de las Comunidades Autónomas incrementaron sus emisiones, tal es el caso de las Islas Baleares, las Islas Canarias, Castilla-La Mancha, Ceuta, Extremadura, La Rioja, Madrid, Melilla, Navarra y Murcia, que incrementaron sus emisiones en, aproximadamente 1.000 miles de toneladas respecto al año 1.995 (ver tabla 5).

De igual modo cabe destacar que en los años 2008 y 2009 las emisiones totales descendieron respecto al 2007 en todas las Comunidades Autónomas, a excepción de las Islas Canarias -aumentó sus emisiones de las 15847 miles de toneladas hasta las 16.511 miles de toneladas en 2008-, las Islas Baleares -produjeron 10.614 miles de toneladas en 2007 y 10.630 miles de toneladas en 2008-, la Rioja -en el año 2007 las emisiones fueron de 3.947 miles de toneladas y en 2008 de 4.423 miles de toneladas-, Navarra -ascendieron de las 7.739 miles de toneladas en 2007 hasta las 7.963 miles de toneladas en 2008, la Región de Murcia -pasó de emitir 11.158 miles de toneladas en 2007 a emitir 12.458 miles de toneladas en 2008- y la Comunidad Valenciana -32.568 miles de toneladas en 2007 frente a las 35.606 miles de toneladas- que en el año 2008 incrementaron sus emisiones como consecuencia del aumento del turismo y del incremento del parque automovilístico, aunque disminuyeron al año siguiente.

A diferencia del resto de los sectores (tabla 6), el transporte, y más concretamente el transporte por carretera (continúa presentando el mayor peso sobre el total de las emisiones de GEI en España) ha incrementado de manera constante y progresiva sus emisiones desde 1990 hasta el año 2009 -pasando de las 61.575,8 miles de toneladas en el año 1990 hasta las 294.118,4 miles de toneladas en el año 2009-. Cabe destacar que en los años 2008 y 2009 las emisiones aumentaron en menor proporción que en los años anteriores; en 2009 las emisiones se incrementaron en 10.000 miles de toneladas aproximadamente, mientras que en los años anteriores los aumentos oscilaban entre los 20.000 miles de toneladas y las 30.000 miles de toneladas. La crisis económica ha provocado un descenso en las matriculaciones de nuevos vehículos si tomamos como referencia la tendencia porcentual de los años anteriores, pero continuaron siendo alcistas a pesar de la reducción de los salarios, de los subsidios y el incremento del paro, entre otros factores, que ha reducido sustancialmente la capacidad adquisitiva de los individuos, repercutiendo en el consumo de estos pero que, sorprendentemente no ha producido una disminución en el uso de los vehículos privados, con lo que las emisiones, lejos 


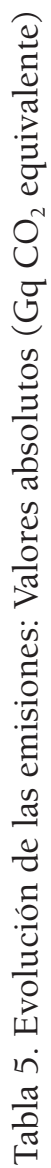

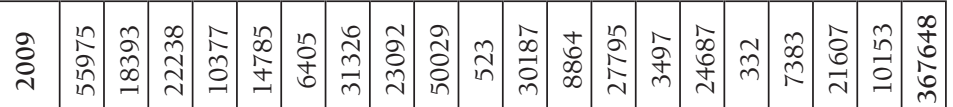

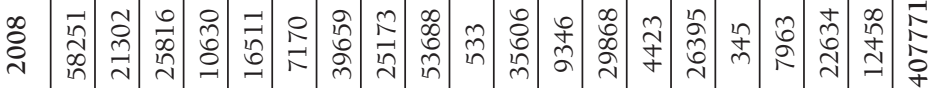

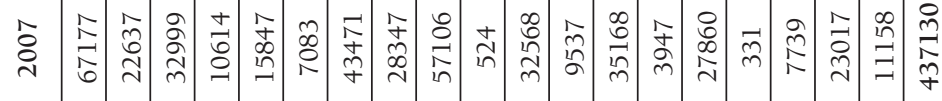

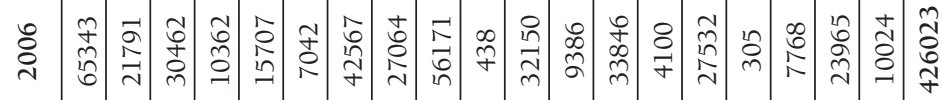

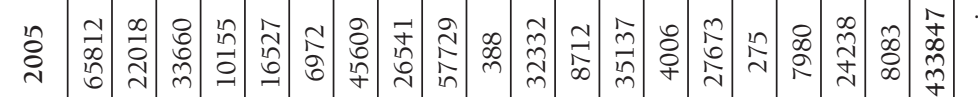

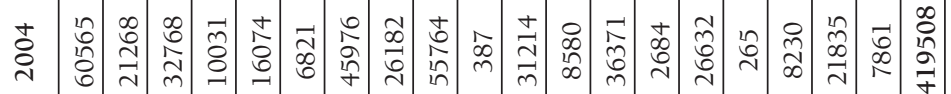

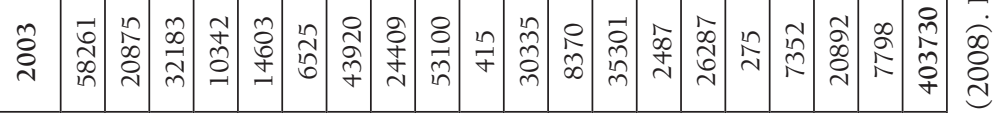

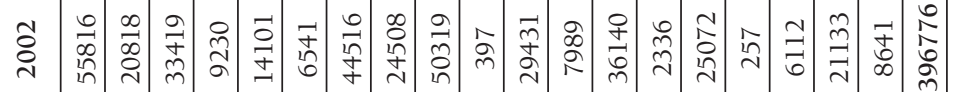

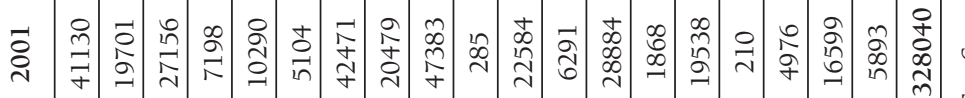

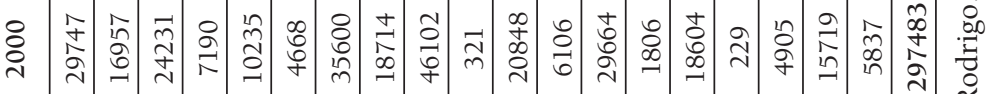

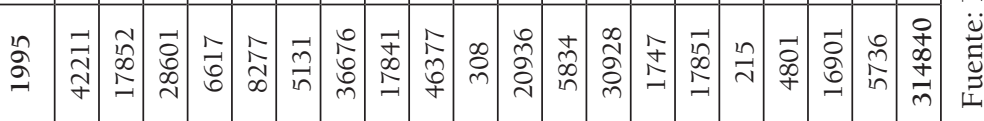

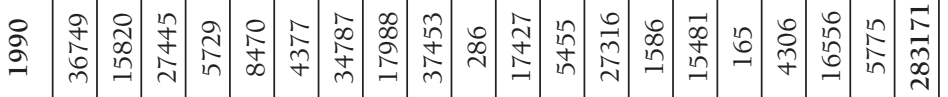

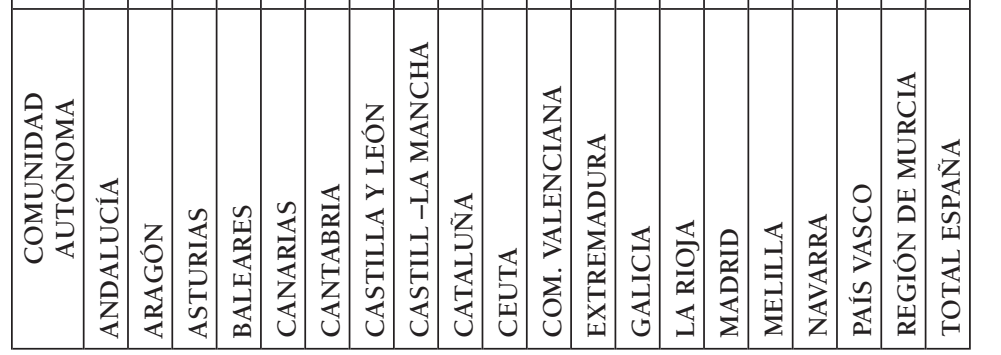




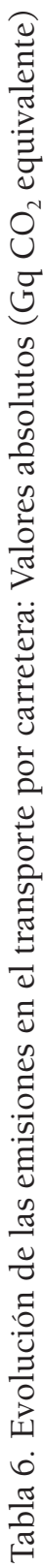

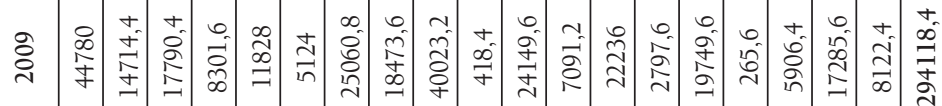

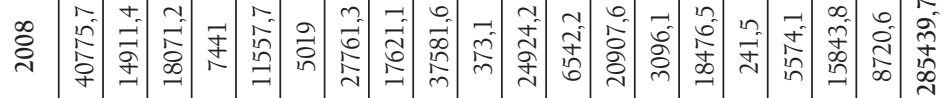

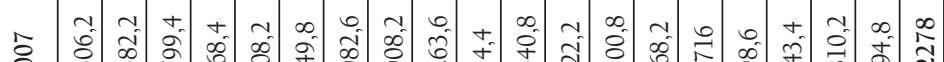

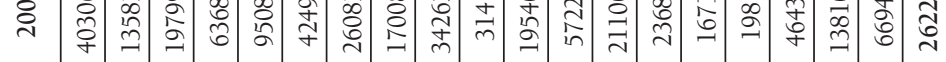

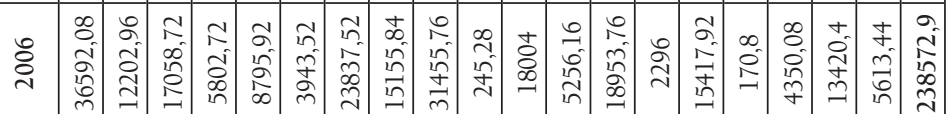

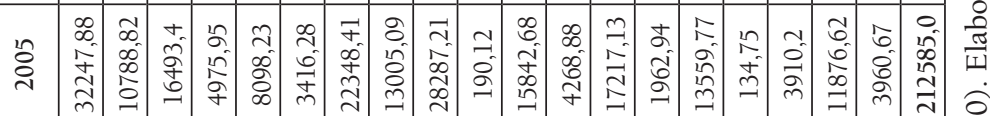

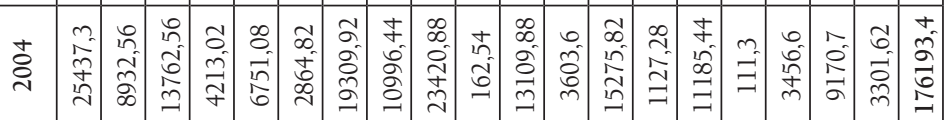

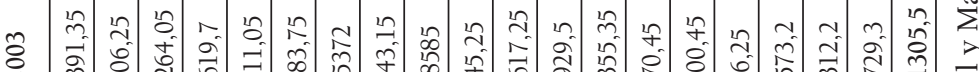

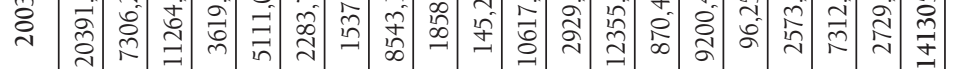

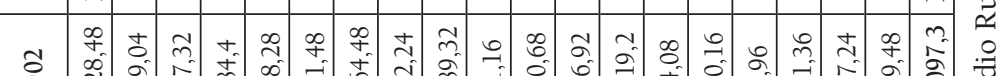

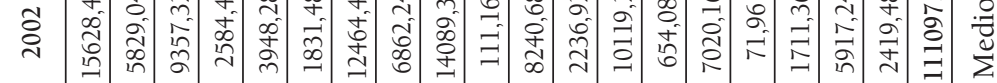

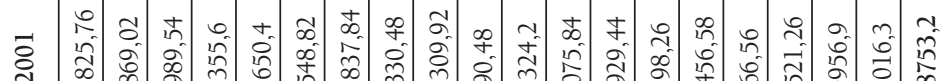

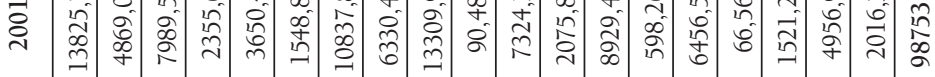

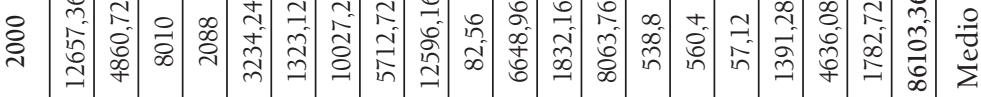

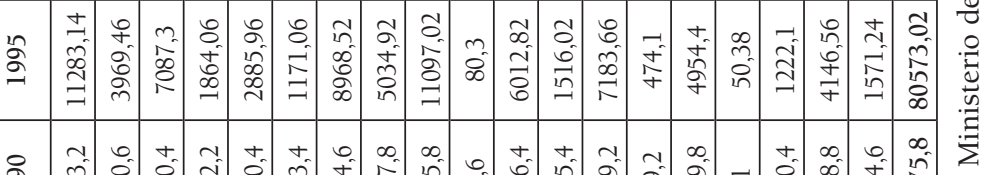

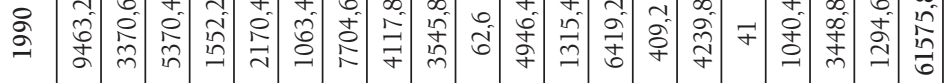

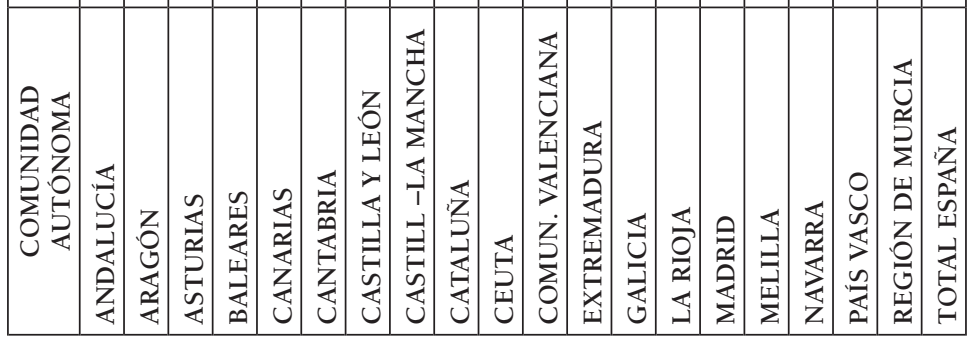


de reducirse como en el resto de los sectores, se han incrementado. Es fundamental destacar que este hecho no se ha sucedido en todas las Comunidades Autónomas, Cataluña emitió 40.023,2 miles de toneladas en el 2009, Castilla y León presentó uno de los mayores aumentos de sus emisiones de toda España pasando de las 7.704,6 miles de toneladas en 1990 hasta las 25.060,8 miles de toneladas en 2009 y la Comunidad Valenciana emitió 24.149,6 miles de toneladas en 2009; estas tres Comunidades son las que más $\mathrm{CO}_{2}$ emitieron en el año 2009 y mayores incrementos.

Por otro lado, junto a las ciudades autónomas de Ceuta (418,4 miles de toneladas) y Melilla (265,6 miles de toneladas), las Comunidades Autónomas Cantabria (5.124 miles de toneladas en 2009, 4.060 mil toneladas más que en 1990) y Navarra (5.906,4 miles de toneladas en 2009 frente a las 1040,4 miles de toneladas de 1990), incrementaron sus emisiones pero en cantidades pequeñas (menos del 1.000 miles de toneladas entre 1990 y 2009) en comparación con Madrid que emitió 19749,6 miles de toneladas en 2009 frente a las 4239,8 miles de toneladas en 1990, Galicia que es una de las Comunidades que más incrementó sus emisiones en las últimas décadas pasando de las 6.419,2 miles de toneladas en 1990 a las 22.236 miles de toneladas en 2009 junto con Aragón que en 1990 emitió 3370,6 miles de toneladas y en 2009 14714,4 miles de toneladas, Asturias que es una de las Comunidades más representativas respecto a las emisiones del transporte por carretera respecto al total de su población y el peso de su economía en el PIB total de España (emitió 5370,4 miles de toneladas en 1990 y 17790,4 miles de toneladas en 2009) o el País Vasco que aumentó sus emisiones en 13.836,8 miles de toneladas entre 1990 y 2009.

\subsection{Comparativa entre las Emisiones de Gases Efecto Invernadero del transporte por carretera y el total de las Emisiones de Gases Efecto Invernadero en las Comunidades Autónomas de España.}

Hoy es por todos conocido, que el transporte por carretera constituye uno de los elementos esenciales de las políticas macroeconómicas de contribuir de manera eficiente y eficaz al desarrollo económico y social, a la vertebración del territorio y a la integración y cohesión del espacio, puesto que su contribución al PIB supone casi un 5\%, si bien es uno de los sectores más contaminantes en España. Si comparamos los distintos datos de emisiones de $\mathrm{CO}_{2}$ a la atmósfera, por parte de todos los sectores de la nuestra economía con las propias emisiones del transporte por carretera, cabe destacar que el peso del sector transporte no sólo está relacionado con la propia movilidad de la población sino también con el resto de actividades empresariales vinculadas 
al transporte, como por ejemplo las fabricas de montaje o reciclaje y las refinerías (de esta forma, destacar que ambas han soportado crecimientos constantes a lo largo de todo el periodo estudiado en el conjunto total de España). Sin embargo, si descendemos a la escala regional encontramos importantes diferencias que responden no sólo a la propia singularidad de la región estudiada, sino a los distintos cálculos de estudio, ya sea respecto del PIB como de la propia población. Para poder analizar de manera concisa la evolución de dichas emisiones, y tomando como base la metodología de estudio analizada anteriormente, debemos hacer distinción entre la evolución temporal (1990-2009) de las emisiones de $\mathrm{CO}_{2}$ respecto a la población y la evolución

Gráfico 3. Comparativa, emisión del GEI por CC.AA. en 2000 y 2009
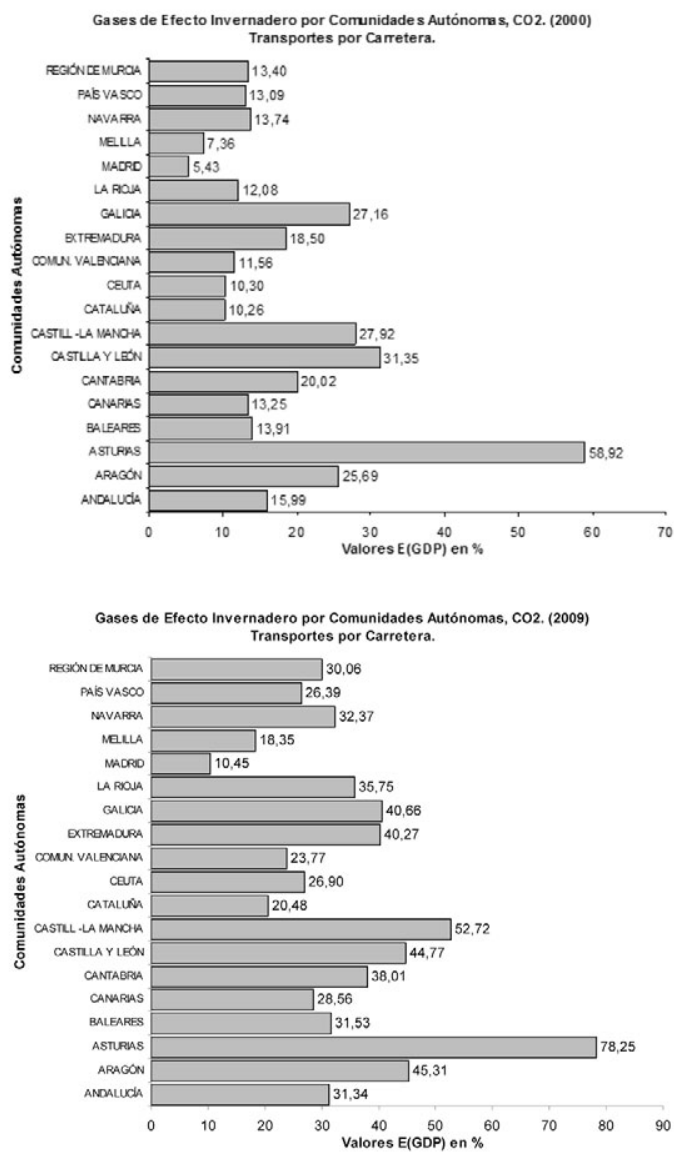

Elaboración propia. 
económica del Producto Interior Bruto, en cada una de las Comunidades Autónomas de España. El incremento porcentual de las emisiones de $\mathrm{CO}_{2}$ respecto al Producto Interior Bruto es un hecho patente en la última década, pero este crecimiento no ha sido homogéneo en todas las Comunidades Autónomas. Cabe destacar que el peso total del sector del transporte por carretera en el PIB en todas sus componentes macroeconómicas (gasto público, empleo, fiscalidad impositiva, consumo e inversión) es de enorme importancia en el marco de la economía nacional e influye en la actividad y desarrollo de otros sectores productivo como el industrial o el turismo.

Tal y como se nos muestra en el gráfico 3, cuyos valores para los años 1990, 2000 y 2009 han sido representados en el mapa 1, es muy significativo el caso concreto de Asturias (que ha pasado del 59\% al 78\% del total de las emisiones del transporte por carreteras respecto del PIB, del total de emisiones) y Castilla la Mancha, las dos Comunidades que más han incrementado sus emisiones de GEI, casi un 30\% más en esta última década. En el caso de Murcia, Navarra, La Rioja, Galicia, Extremadura, Baleares y Aragón presen$\tan$ incrementos de un $20 \%$, aproximadamente, en sus emisiones de $\mathrm{CO}_{2}$. Y

Mapa 1. Gases de Efecto Invernadero en España en 1990, 2000 y 2009

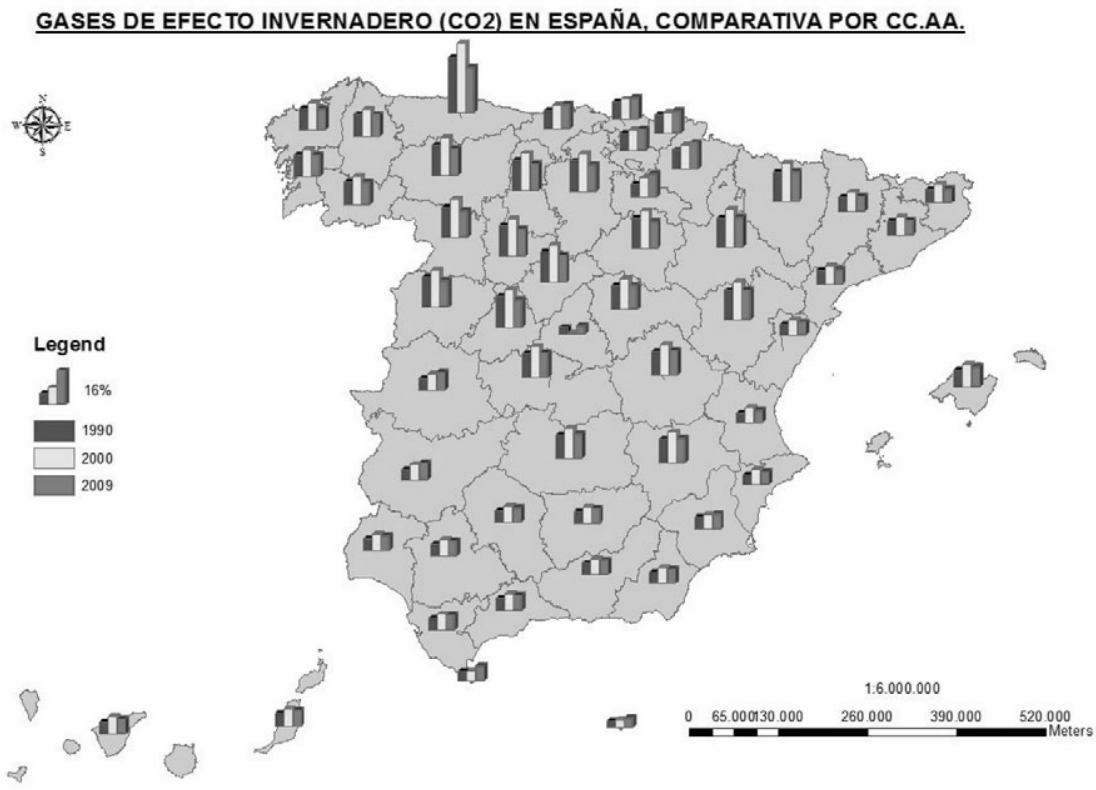

Fuente: Producto Interior Bruto de 1990, 2000 y 2009. Elaboración propia. 
llama la atención los casos concretos de Madrid y Cataluña que apenas han aumentado sus emisiones en un $7 \%$ en estos últimos diez años, a pesar que el parque automovilístico ha crecido más proporcionalmente que si tomamos como base el Producto Interior Bruto.

Una de las principales causas la podemos encontrar en el «boom urbanístico» de esta última década, a nivel nacional, que no sólo ha supuesto un aumento en el número de viviendas totales en áreas urbanas sino que ha promovido la expansión territorial de los núcleos poblacionales hacia zonas no urbanas o zonas rurales y despobladas en origen, favoreciendo un urbanismo insostenible, configurado por casas individuales, adosados, urbanizaciones o construcciones en hilera en medio de «la nada», con lo que, al no disponer de servicios básicos, tienden a utilizar el medio de transporte privado por carretera para trasladarse a sus centros de trabajo, de estudio, de ocio, de esparcimiento, cultural o de consumo, incrementando así las emisiones de Gases Efecto Invernadero. Otro de los factores, ha sido el aumento de la venta de vehículos monovolúmenes, mayores inversiones en infraestructuras y las mejores relaciones precio-consumo-independencia del transporte por carretera.

La presente tabla presenta los resultados de las tasas de reducción ponderadas por el PIB de cada una de las Comunidades Autónomas con miras hacia el 2012 y el 2020, tras emplear la fórmula $E(G D P)_{i, t}=\frac{G H G_{i, t}}{G D P_{i, t}}\left(\mathrm{tCO}_{2}\right.$ $\mathrm{EQ}$ / millones $€$ ), teniendo en cuenta que cuanto mayores sean los índices de emisión inicial del país, por el PIB, mayores son sus coeficientes de reducción.

Atendiendo a los datos recogidos en la tabla 7 , podemos afirmar que para el 2012, lejos de reducirse las emisiones respecto al año 1990, éstas van a incrementarse considerablemente en todas las Comunidades Autónomas. Los mayores aumentos durante este periodo 1990-2012 se producirán en las Comunidades Autónomas de Andalucía, Cataluña, País Vasco y Navarra, mientras que las Ciudades Autónomas de Ceuta y Melilla junto con las Comunidades Autónomas de Cantabria, Aragón y Asturias son las que menores cambios porcentuales tendrán en 2012 respecto al año 1990. Con ello, podemos afirmar que no es factible el cumplimiento del Protocolo de Kioto de reducir las emisiones de $\mathrm{CO}_{2}$ un 8\% en el 2012 tomando 1990 como año base. Sin embargo, a largo plazo, en el año 2020, la tendencia de las emisiones tenderá a irse reduciendo de manera progresiva hasta alcanzar niveles inferiores a los del año 1990. Como nos muestra la tabla 7, aquellas Comunidades que emiten mayores niveles de GEI serán las que más reduzcan sus emisiones, tal es el caso de Cataluña, Navarra, Castilla y León y Andalucía, entre otras. 


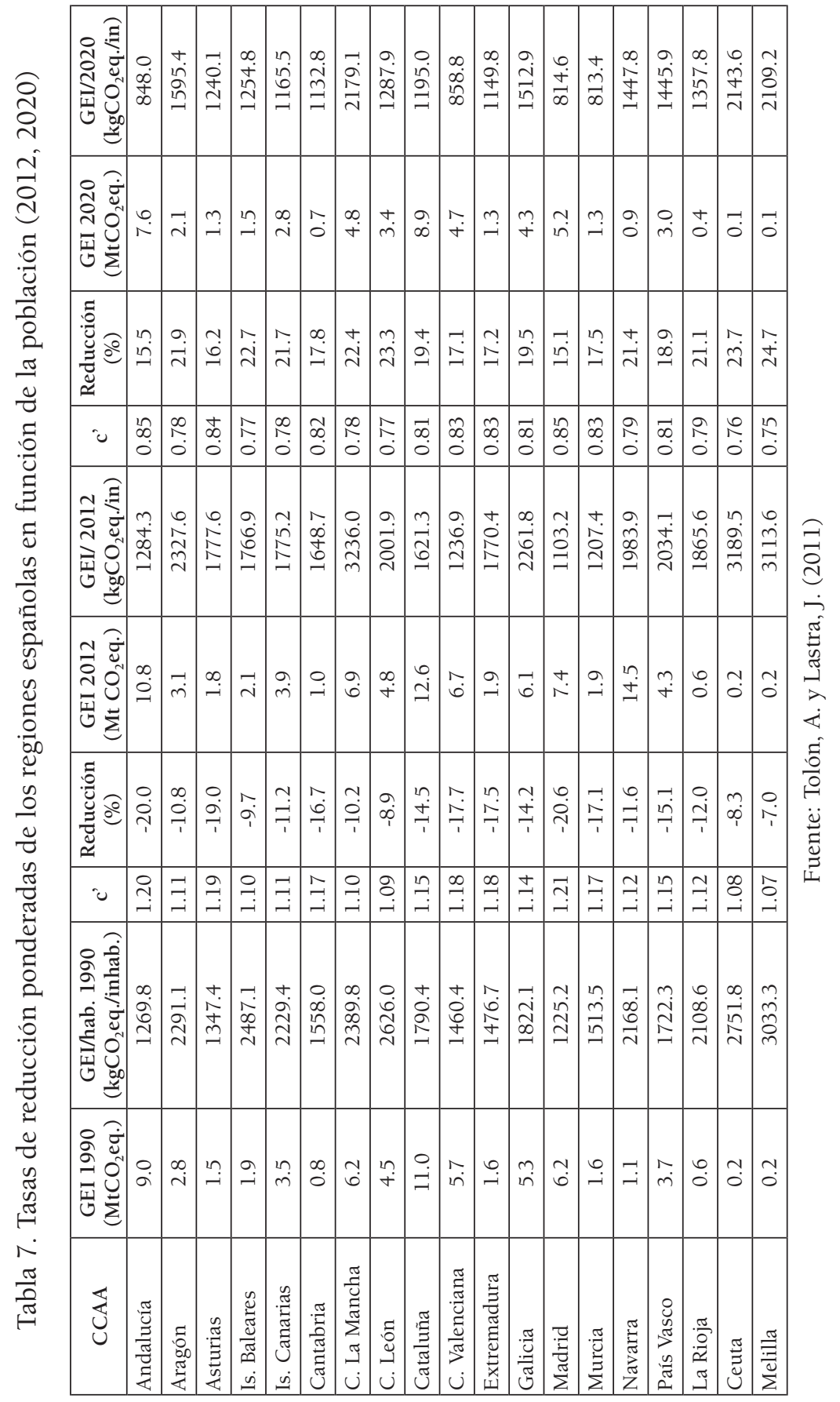


Es preciso hacer referencia a la Comunidad de Madrid que, pese a ser la capital del Estado presenta niveles muy inferiores a los de las comunidades más contaminantes, como consecuencia del escaso peso de industrias termoeléctricas y refinerías, con lo que el total de las emisiones de esta comunidad provienen fundamentalmente del transporte por carretera, de las emisiones domésticas y de su industria transformadora.

Respecto a la vinculación entre las emisiones de GEI y la población podemos afirmar que, en algunas Comunidades Autónomas, la relación entre el total de las emisiones, tanto a nivel nacional como comarcal, es inversamente proporcional al total de la población residente en una determinada Comunidad (los porcentajes de cada una de las Comunidades han sido hallados respecto al total de España). A pesar de la implantación de nuevos planes integrales y proyectos para disminuir estas emisiones de $\mathrm{CO}_{2}$ en los núcleos urbanos, no sólo en España sino en toda la Unión Europea, basados en fundamentalmente en el uso del transporte público, campañas de concienciación pública del impacto que tiene el transporte privado en el medioambiente, la flexibilización de algunos horarios de trabajo para reducir el número de viajes innecesarios, la creación de nuevas y mejores infraestructuras...

Tal y como se nos muestra en los gráficos 4 y 5 , la tendencia de las emisiones de $\mathrm{CO}_{2}$ entre 1990 a 2009, ha sido creciente en todas las Comunidades Autónomas a excepción de Asturias que ha visto reducidas sus emisiones respecto a la población, en casi un 5\%, como consecuencia del leve aumento de su población en comparación con el resto de España (la población de Asturias representa el 2,4\% del total de España). A pesar de ello es una de las regiones más intensivas en emisiones, si tenemos en cuenta el cálculo respecto a la propia comunidad asturiana vemos que la tendencia ha sido alcista (se incrementó un 21,5\%), muy por encima de los valores permitidos en el Protocolo de Kioto. Este importante aumento es producido tanto por las numerosas centrales térmicas que se localizan en su territorio como por el sector industrial fundamentado en industrias básicas de aluminio, carbón, siderurgia, cementeras, papeleras, etc. Respecto a su incidencia en el PIB (gráficos 6 y7), es representativo que el mayor peso de las emisiones no recaía sobre el transporte por carretera sino que estas emisiones provienen fundamentalmente de lo expuesto con anterioridad, de su sector intensivo industrial (principalmente por sus industrias del carbón y del metal), por eso su peso global respecto al total del PIB era muy importante (cuestión que ha variado en las últimas décadas), mientras que su porcentaje se reducía sustancialmente en cuanto a su emisiones por transporte por carretera que apenas representa un $6,8 \%$ 
Gráfico 4. Comparativa emisiones de GEI por CC.AA. entre transporte por carretera y conjunto total de emisiones de $\mathrm{CO} 2$ (valores $\mathrm{E}(\mathrm{ln} \mathrm{h})$ en $\mathrm{tCO}_{2} \mathrm{EQ} /$ habitantes), 1990)

Gases de Efecto Invernadero por Comunidades Autónomas, CO2 (1990) Transportes por Carretera

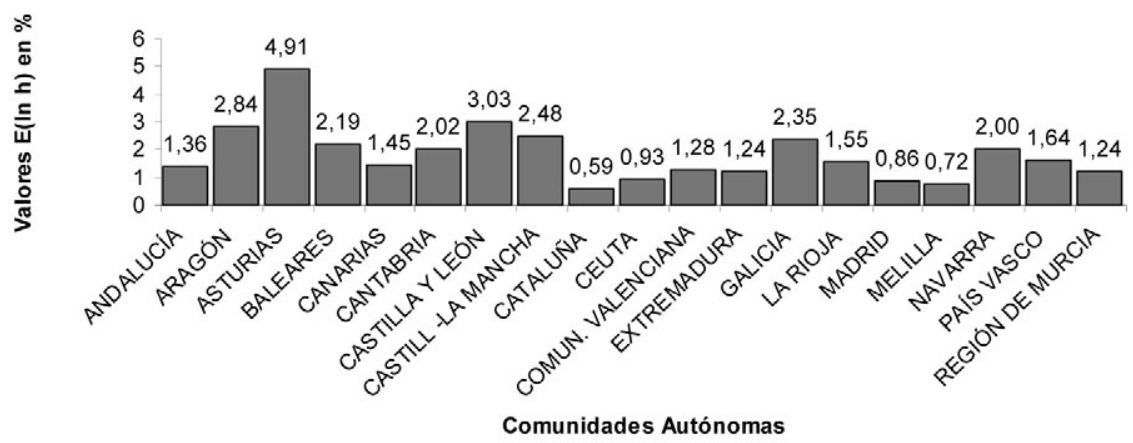

Gases de Efecto Invernadero por Comunidades Autónomas, CO2 (1990)

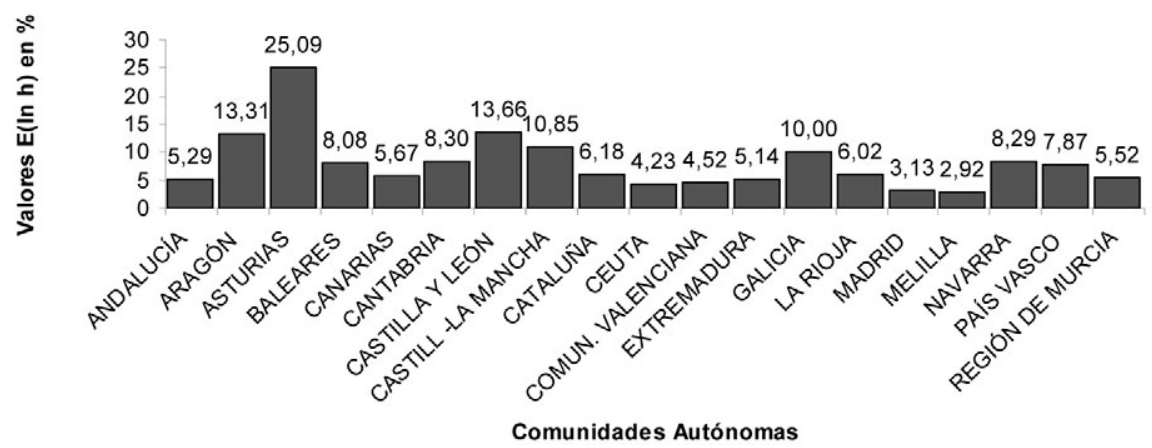

Elaboración propia.

sobre el total en el año 1990, mientras que en el año 2009 ha pasado a tener un peso muy importante respecto del total de emisiones situándose en un $8 \%$.

Las Ciudades Autónomas de Ceuta y Melilla son las que soportan menor carga de emisiones de $\mathrm{CO}_{2}$ (aunque han visto incrementadas sus emisiones en los últimos años fundamentalmente por las emisiones de Endesa) como consecuencia fundamental de su reducido territorio y su baja población que apenas representa el 0,17\% respecto al total de España en Ceuta y el 0,15\% en Melilla (gráficos 4 y 5). Respecto del PIB las emisiones de $\mathrm{CO}_{2}$ se han incrementados sustancialmente, siendo el transporte por carretera el principal elemento de dicho incremento, ya que la mejora económica en estos últimos 
años (gráficos 6 y 7), junto con el aumento del turismo ha favorecido el aumento poblacional y la movilidad, sobre todo, entre el territorio español y el africano.

Andalucía es un caso curioso puesto que, a pesar de tener un territorio extenso, muy poblado (representa el 15\% de población de España), un centro de reclamo turístico y contar con una buena dotación industrial apenas ha visto incrementar porcentualmente sus emisiones en relación con su población total (ya que, como vimos anteriormente, Andalucía había incrementado sus emisiones en un $85 \%$ respecto del total de España en estos veinte años). El peso total de las emisiones recae principalmente, en el propio transporte por carretera, que representa un 1,32\% respecto del total de las emisiones en el año 1990 y ha aumentado hasta 5,6\% (tablas 4 y 5), por lo que se puede afirmar que el $80 \%$ de las emisiones totales en Andalucía provienen del transporte.

En Aragón, las emisiones de GEI, han aumentado respecto al año 1990, pero en un porcentaje muy pequeño respecto al total de España (por niveles inferiores a la media española), como consecuencia del peso de su industria del carbón. De igual modo, el crecimiento de las nuevas instalaciones de energía eólica ha servido de sustitutivos a otras fuentes de energía más contaminantes lo que ha favorecido la contención de las emisiones totales. Su población apenas supones el 3\% respecto del total de España, pero ha ido aumentando a lo largo del periodo estudiado, ejerciendo una mayor presión en el territorio. En cuanto al transporte por carretera, observamos la misma tendencia que en el resto de las Comunidades, un aumento progresivo del peso global de dichas emisiones, que representan el mayor porcentaje de las emisiones en Aragón (pasó del 2,84\% en 1990 al 11,52\% en 2009).

En la zona insular, tanto en Canarias como en las Islas Baleares, la presión del turismo ha incidido mucho en el incremento de los valores de sus emisiones con motivo del aumento de la poblacional estacional. De manera más concreta, en Canarias, a pesar de no tener industrias intensivas en energía, presenta uno de los incrementos más altos de España, como consecuencia de la generación de electricidad con combustibles fósiles y de las centrales termoeléctricas, que junto al turismo y a los transportes en general y por carretera en particular (representa más del 60\% de las emisiones totales de la isla), han aumentado sus emisiones más de la media nacional. Mientras que en las Islas Baleares, si encontramos industrias intensivas en energía e industrias del sector energético, pero el mayor peso de todas las emisiones se derivan, junto con el turismo, del aumento porcentual de las emisiones de $\mathrm{CO}_{2}$ provenientes del transporte por carretera. 
Gráfico 5. Comparativa emisiones de GEI por CC.AA. entre transporte por carretera y conjunto total de emisiones de $\mathrm{CO} 2$ (valores $\mathrm{E}(\mathrm{ln} \mathrm{h})$ en $\mathrm{tCO}_{2} \mathrm{EQ} /$ habitantes), 1990)

Gases de Efecto Invernadero por Comunidades Autónomas, CO2 (2009) Transportes por Carretera

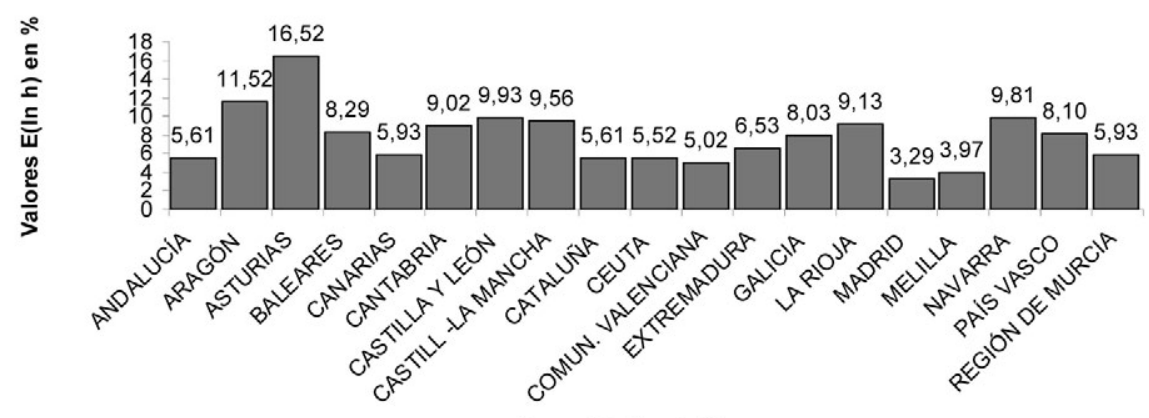

Comunidades Autónomas

Gases de Efecto Invernadero por Comunidades Autónomas, CO2 (2009)

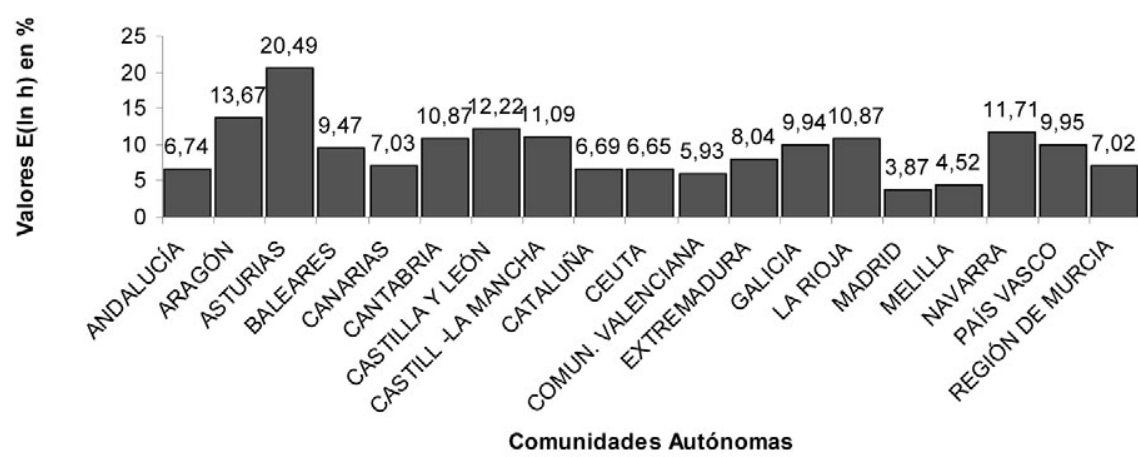

Elaboración propia.

En la Comunidad Autónoma de Cantabria, sigue la misma tendencia de las demás Comunidades, ha incrementado sus emisiones de $\mathrm{CO}_{2}$ a lo largo de todo el periodo estudiado entorno a un 35\%. Junto con el importante peso que tiene las industrias químicas, papelera y de cemento en la zona (ya que tras la instalación de numerosos aerogeneradores desde el año 2007, las emisiones de las centrales eléctricas se redujeron considerablemente respecto del total) destaca como emisor principal el transporte por carreteras, ya que el aumento poblacional (gráficos 4 y 5) y las mejoras en la economía de la región ha favorecido el incremento de la movilidad y el desarrollo económico de la zona, expansionando la demanda de vehículos. El caso de Cantabria, 
atendiendo a la vinculación existente entre las emisiones de $\mathrm{CO}_{2}$-total y vinculada al transporte por carretera- y el Producto Interior Bruto (gráficos 6 y 7) nos muestras diferencias sustanciales entre los resultados obtenidos en el año 1990 y el 2009 de las emisiones globales de GEI, ya que en el año 1990 las emisiones representaban casi un 18\% del total de España, y han descendido progresivamente, hasta alcanzar un 4,8\% en 2009, viéndose incrementado el peso del transporte por carretera como fuente principal de dichas emisiones.

En el caso concreto de Castilla y León, los índices poblacionales, respecto de la media española han descendido en las últimas décadas, con lo que, ha pesar de presentar niveles de emisiones muy altos (como ya vimos con anterioridad se encontraba en la tercera posición tras Andalucía y Cataluña, por sus refinerías y la central termoeléctrica) ha ido reduciendo progresivamente el total de sus emisiones de $\mathrm{CO}_{2}$ equivalentes, desde las 34.787 miles de toneladas en 1990 hasta los 31.326 miles de toneladas en 2009, siendo el transporte su principal foco de emisiones, tal y como muestran los gráficos 4 y 5; por lo que su peso respecto a la población es alta respecto a la media española pero no en la medida en que debería serlo atendiendo a su extensión territorial. De igual modo, atendiendo a las emisiones respecto al PIB de Castilla y León (gráfico 6 y 7), ha descendido de manera muy brusca en las dos últimas décadas pasando del 13,77\% al 5,60\%, aunque el peso del transporte por carretera sigue siendo la fuente principal de emisiones.

La Comunidad Autónoma de Cataluña, muestra un claro incremento de sus emisiones de $\mathrm{CO}_{2}$, posicionándola entre las tres primeras Comunidades emisoras, pero si analizamos su peso respecto a la población total residente (16\% del total de España), vemos que su crecimiento porcentual no supera la media nacional, como consecuencia de una escasa presencia de industrias intensivas en emisiones y consumo energético, con la excepción de las tres centrales nucleares (solo disponen de una central termoeléctricas de carbón) que emiten no solo la mayor parte de los GEI sino que también generan residuos radiactivos. Respecto al PIB las emisiones han descendido considerablemente en las últimas décadas y, en ambos casos, (población y PIB) provienen del transporte por el aumento porcentual del transporte por carretera, que ha pasado de configurar el 0,43\% de las emisiones totales respecto del PIB al $2,18 \%$ del 2,56\% de las emisiones totales, como nos muestran las tablas 6 y 7 ).

Las emisiones de gases de invernadero han aumentado en la Comunidad Valenciana un $85 \%$ en el periodo estudiado, uno de los mayores crecimientos de España. Las mayores emisiones provienen, en menor medida, de la central nuclear generadora de electricidad que, a su vez, plantea graves problemas de radiactividad, junto con las industrias del sector energético. El 
Gráfico 6. Comparativa emisiones de GEI por CC.AA. entre transporte por carretera y conjunto total de emisiones de $\mathrm{CO} 2$ (valores $\mathrm{E}(\mathrm{GDP})$ en $\mathrm{tCO}_{2} \mathrm{EQ} /$ millones $€$ ), 1990)

Gases de Efecto Invernadero por Comunidades Autónomas, CO2 (1990)

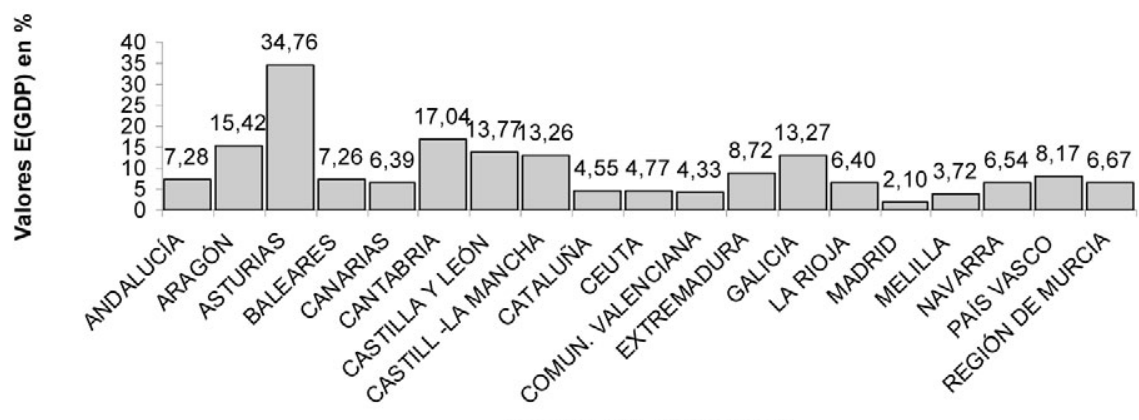

Comunidades Autónomas

Gases de Efecto Invernadero por Comunidades Autónomas, CO2 (1990) Transporte por carretera

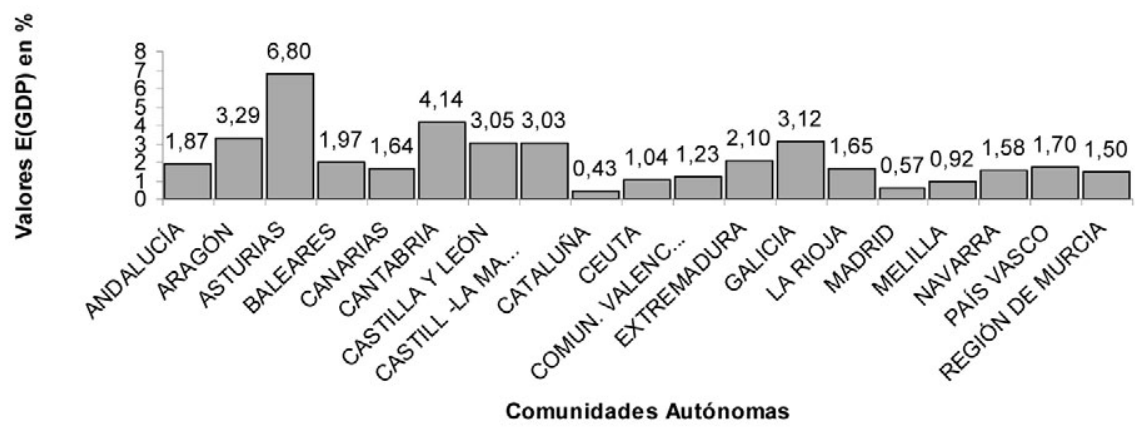

Elaboración propia.

mayor problema atendiendo a este aumento de las emisiones proviene fundamentalmente del transporte por carretera que presenta el $60 \%$ de las emisiones, habiendo aumentado más que considerablemente con respecto a 1990. Atendiendo a su población, el peso total de las emisiones de $\mathrm{CO}_{2}$ presentó un ligero aumento en el año 2009 respecto a los niveles iniciales de 1990 (pasando del 4,5\% en 1990 al 5,9\% en el año 2009), mientras que respecto a su peso en el PIB, vio reducidas sus emisiones totales a la mitad mientras que las emisiones del transporte por carretera se duplicaron respecto a 1990 (ver tablas 6 y 7 ). 
Las emisiones de gases de invernadero han aumentado en Extremadura un porcentaje muy superior a la media nacional, mayoritariamente por la producción de las centrales hidroeléctricas y la central nuclear de Almaraz. Tomando como referencia la población (tablas 4 y 5), Extremadura han aumentado considerablemente pasando de un casi $6 \%$ al $8 \%$ en el periodo estudiado, como consecuencia del progresivo aumento de la población que ha ejerciendo una mayor presión en el territorio, mientras que respecto al PIB ha disminuido pasando de un 8,72\% al 5,03\% en 2009 (tablas 6 y 7 ). En cuanto al transporte por carretera, observamos la misma tendencia que en el resto de las Comunidades, un aumento progresivo del peso global de dichas emisiones, que representan el mayor porcentaje de las emisiones en Extremadura (pasó del 1,24\% en 1990 al 6,53\% en 2009).

Las emisiones de gases de invernadero han aumentado en Galicia entre 1990 y 2009, en un porcentaje superior a lo permitido en el Protocolo de Kioto. El mayor incremento (aunque por debajo de la media nacional) provienen fundamentalmente de las industrias de celulosa ENCE de Pontevedra, la alúmina se San Ciprián en Pontevedra, la central térmica y la refinería de la Coruña, con lo que podemos afirmar que las mayores emisiones se concentran en las ciudades de Pontevedra y la Coruña, con lo que nos permite realizar una línea divisoria entre los municipios costeros y el interior de la Comunidad. Atendiendo a la población total de la Comunidad Autónoma, las emisiones se han reducido en un porcentaje muy pequeño que no alcanza el $1 \%$ pasando del 10\% en 1990 al 9,2\% en 2009. Respecto al PIB la tendencia ha sido la misma, se ha reducido, pero un porcentaje mucho mayor, descendiendo las emisiones en más de la mitad entre 1990 y 2009. Respecto a las emisiones del transporte por carretera, al igual que en el resto de las Comunidades Autónomas, supone el 80\% de las emisiones totales. El aumento de dichas emisiones provenientes del transporte por carretera se han incrementado en las zonas más costeras y dinámicas desde la perspectiva económica de la Comunidad, mientras que las zonas más deprimidas del interior apenas han visto incrementadas sus emisiones.

Las emisiones de gases de invernadero han aumentado en Madrid un 85\% entre 1990 y 2009. A pesar de las casi inexistentes industrias del sector energético, el peso de las emisiones de la Comunidad han ascendido por encima de la media nacional como consecuencia de la proliferación de centrales de ciclo combinado, de las emisiones de usos domésticos y, fundamentalmente, por las emisiones de $\mathrm{CO}_{2}$ del transporte por carretera, que se han visto incrementadas en un $80 \%$ respecto a 1990 y representan un $70 \%$ de las emisiones totales de la ciudad. En cuanto al peso de las emisiones del transporte por 
Gráfico 7. Comparativa emisiones de GEI por CC.AA. entre transporte por carretera y conjunto total de emisiones de $\mathrm{CO} 2$ (valores $\mathrm{E}(\mathrm{GDP})$ en $\mathrm{tCO}_{2} \mathrm{EQ} /$ millones $€$ ), 2009)

Gases de Efecto Invernadero por Comunidades Autónomas, CO2 (2009)

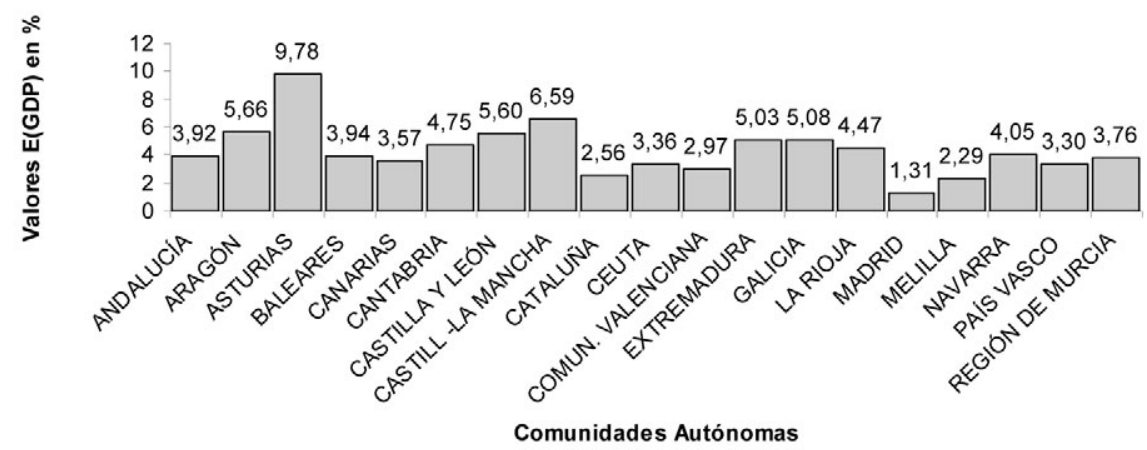

Gases de Efecto Invernadero por Comunidades Autónomas, CO2 (2009) Transporte por carretera

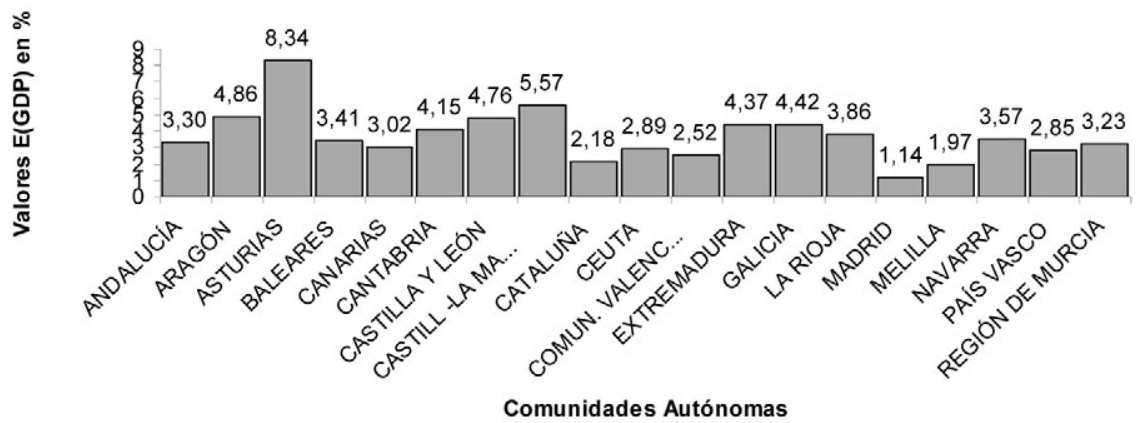

Elaboración propia.

carretera respecto a la población (tablas 4 y 5), estas se han visto incrementadas en casi un 3\% respecto al año 1990, mientras que si tomamos como base el PIB vemos un ligero aumento del 0,5\% en 1990 al 1,14\% en 2009 (resultado inversamente proporcional al descenso de las emisiones de $\mathrm{CO}_{2}$ total entre 1990 y 2009).

Las emisiones de gases de invernadero en la Comunidad Autónoma de Murcia se han incrementado más que considerablemente, por encima incluso de la media nacional en el periodo de estudio. Junto con los sectores energéticos de centrales de ciclo combinado y refinerías, ha cobrado gran importancia 
en este aumento sustancial de las emisiones, el propio sector primario (agricultura y ganadería) y el sector del transporte por carretera. Este último incrementó sus emisiones, tomando como base la población (tablas 4 y 5) del 1,24\% en 1990 hasta el casi 6\% en el año 2009. Tomando como base el PIB podemos observar como las emisiones de GEI en la Región de Murcia se incrementó del 1,5\% en 1990 hasta el 3,5\% en 2009. Es una de las pocas Comunidades en las que ha aumentado considerablemente tanto respecto a la población como sobre el Producto Interior Bruto.

En Navarra, las emisiones de gases efecto invernadero se han incrementado por encima de la media nacional, a pesar de las mejoras en el desarrollo de la energía eólica, como consecuencia del aumento de las emisiones de las centrales de ciclo combinado y la industria cementera. Respecto a la población, las emisiones totales de $\mathrm{CO}_{2}$, se incrementó del 8,29\% en 1990 al 11,11\% en el 2009 como consecuencia del aumento porcentual de la población de la Comunidad con respecto al total nacional. Respecto al PIB, se redujeron en un $2 \%$ respecto del 2009. El peso total del transporte por carretera es del $80 \%$ respecto del total de las emisiones de la Comunidad.

Las emisiones de gases de invernadero en el País Vasco se han incrementado sustancialmente aunque por debajo de los niveles de la media nacional. El mayor peso de estas emisiones provienen fundamentalmente sobre el sector industrial vinculado a la refinería de Somorrostro, las térmicas y las nuevas centrales de ciclo combinado. Junto al sector industrial, el incremento de la población ha favorecido el aumento de las emisiones domésticas y, sobre todo, por el transporte por carretera, como consecuencia de un crecimiento insostenible que hace primordial el uso de los vehículos para poder comunicar los núcleos urbanos con las viviendas rurales. Tomando como base la población, las emisiones de $\mathrm{CO}_{2}$ se han incrementando en más de un $2 \%$ respecto al año 1990, mientras que respecto al PIB también han sufrido aumentos pero en menos de un 1\% entre 1990 y 2009 (ver tablas 6 y 7).

\section{EL TRANSPORTE POR CARRETERA EN ESPAÑA Y SU HUELLA ECOLÓGICA}

La Huella Ecológica es un instrumento, desarrollado por Wackernagel \& Rees, con el que se pretende calcular, estudiar y analizar la cantidad de bienes y servicios naturales y ambientales que demanda -consume- y desecha una persona o población en una determinada región o país; por lo que se define como el área de terreno que se necesita para atender a las necesidades ilimitadas, por parte de una sociedad, de recursos naturales y ambientales limitados, desde los conceptos óptimos de eficiencia y equidad. Estos cálculos de 
Huella Ecológica se fundamentan en dos valoraciones importantes (Garraín, D.): midiendo la mayoría de los recursos que se consumen y los desechos que se generan; y que el consumo y producción de desechos se puede traducir en el área biológicamente productiva necesaria para que puedan realizarse dichas funciones.

En nuestro caso de estudio, la Huella Ecológica del transporte por carretera atendiendo a sus emisiones de Gases Efecto Invernadero, sería la cantidad total de terreno con cubierta vegetal necesaria para absorber todo el $\mathrm{CO}_{2}$ que genera el propio transporte por carretera. En el último año, el transporte por carretera ha emitido un valor aproximado que oscila entre el 80 y el $85 \%$ del total de las emisiones de Gases Efecto invernadero en el año 2009, con lo que la superficie de territorio deshabitado, configurado exclusivamente por masa forestal calculada para neutralizar dichas emisiones equivaldrían a un $73 \%$ de la masa forestal de España y casi a un $40 \%$ del territorio nacional.

Para poder realizar una estimación de la Huella Ecológica respecto de las Emisiones de Gases de Efecto Invernadero, se ha de agrupar las distintas presiones sobre el medio y traducirlas a un único número común que designe la superficie biológicamente productiva, por lo que hay que hacer extensivo el cálculo a todos o a la mayoría de los recursos naturales del territorio que realiza la actividad económica de un país, se podrá conocer con bastante aproximación la magnitud del impacto en términos de superficie de biosfera necesaria para sostener su economía y eliminar sus desechos. Existen seis dimensiones básicas en el cálculo de la huella ecológica (Garrían, D.):

1) Superficie cultivada: área para producir los vegetales que se consumen, la cual constituye la tierra más productiva ecológicamente, y genera la mayor producción neta de biomasa utilizable por las comunidades humanas.

2) Superficie artificial: área utilizada para urbanización, infraestructuras o centros de trabajo.

3) Superficie necesaria para proporcionar alimento vegetal.

4) Superficie necesaria para pastos que alimentan ganado.

5) Superficie marina necesaria para producir pescado.

6) Superficie de bosque necesaria para servir de sumidero del $\mathrm{CO}_{2}$ emitido a causa del consumo energético.

Para el cálculo de la Huella Ecológica del transporte por carretera se puede aplicar una formulación matemática que interrelacione el ratio energía/ hectáreas de masa forestal con el consumo de combustible de los vehículos que transitan por un determinado territorio. Siguiendo dicha metodología, 
el profesor Daniel Garrían estipuló que en España dicha Huella es de 71 GJ/ ha/año, es decir, que una hectárea de bosque puede capturar anualmente las emisiones de $\mathrm{CO}_{2}$ generadas por el consumo de $71 \mathrm{GJ}$ de combustible líquido. Aunque también se pueden emplear otros cálculos a partir de las emisiones de $\mathrm{CO}_{2}$ de los vehículos y la aplicación del ratio de absorción de carbono de la masa forestal, con lo que la Huella Ecológica de España se aproximaría a $5,21 \mathrm{t} \mathrm{CO}_{2}$ /ha/año.

Por lo que, tomando como referencia un litro de combustible (35 MJ de energía), homogeneizando los diferentes tipos de suelo y multiplicando la Huella Ecológica de cada uno de ellas por la productividad media global de un área bioproductiva, en relación con la productividad media global de todas las áreas bioproductivas, se obtiene un valor final de 56,48 millones de hectáreas anuales, para el total de las emisiones de $\mathrm{CO}_{2}$ (un total para toda España de 294.118,4 miles de toneladas) emitidas por el sector del transporte por carretera en 2009.

\section{A MODO DE CONCLUSIÓN}

De la investigación anteriormente descrita pueden colegirse las siguientes conclusiones; a saber:

Primera conclusión: El total de las emisiones de Gases Efecto Invernadero del transporte por carretera ha experimentado un crecimiento constante a lo largo de las últimas décadas, siendo uno de los componentes que configuran el conjunto de las emisiones de GEI en España, con mayor peso relativo. Sin embargo, las emisiones de $\mathrm{CO}_{2}$ en su conjunto, presentan un ligero descenso en los dos últimos años del periodo de estudio; la causa directa la encontramos en la crisis económica que está padeciendo nuestro país junto con un «cambio significativo en el patrón cultural», lo que ha favorecido la reducción de las emisiones en unos porcentajes relativamente pequeños, si bien no menospreciables.

Segunda conclusión: Al igual que ocurre en otros países de la Unión Europea, España dista bastante de alcanzar los niveles de emisiones propuestas en el Protocolo de Kioto, tanto para el año 2012 como para el no tan lejano 2020. Pese a todo, si se aplica a lo largo de los próximos años una adecuada política, que abarque desde la descentralización como del trabajo conjunto de las distintas Comunidades Autónomas con el Gobierno Central hasta una gestión más equilibrada del transporte por carretera, más programas severos de reducción de emisiones de GEI, desde nuestra investigación se concluye que aún es posible alcanzar los objetivos propuestos o, por lo menos, aproximarse a ellos (no debemos olvidarnos que en épocas de expansión, crecimiento y 
bonanza económica, se genera una tendencia alcista de las emisiones de Gases Efecto Invernadero, sin embargo, en momentos de crisis como el que vivimos las emisiones tienden a reducirse considerablemente).

Tercera conclusión: El peso total de las emisiones de $\mathrm{CO}_{2}$ del transporte por carretera respecto del total de emisiones en España, es muy importante. Cabe destacar que, al dar comienzo, la crisis económica en España, la tendencia alcista de las últimas décadas toca techo y comienza a descender, aunque de manera poco brusca, desde las 440.000 miles de toneladas en el año 2007 hasta las 370.000 miles de toneladas en el año 2009 (pese a todo, no debemos olvidar que en los Gases Efecto Invernadero, el $\mathrm{CO}_{2}$ presentan emisiones que triplican los valores recomendados en el Protocolo de Kioto).

Cuarta conclusión: El incremento porcentual de las emisiones de $\mathrm{CO}_{2}$ respecto al Producto Interior Bruto es un hecho patente en la última década, pero este crecimiento no ha sido homogéneo en todas las Comunidades Autónomas. Cabe destacar que el peso total del sector del transporte por carretera en el PIB en todas sus componentes macroeconómicas (gasto público, empleo, fiscalidad impositiva, consumo e inversión) es de enorme importancia en el marco de la economía nacional e influye en la actividad y desarrollo de otros sectores productivo como el industrial o el turismo.

Quinta conclusión: En el último año, el transporte por carretera ha emitido un valor aproximado que oscila entre el 80 y el $85 \%$ del total de las emisiones de Gases Efecto invernadero en el año 2009, con lo que la superficie de territorio deshabitado, configurado exclusivamente por masa forestal calculada para neutralizar dichas emisiones equivaldrían a un $73 \%$ de la masa forestal de España y casi a un $40 \%$ del territorio nacional. Por lo que, tomando como referencia un litro de combustible (35 MJ de energía), homogeneizando los diferentes tipos de suelo y multiplicando la Huella Ecológica de cada uno de ellas por la productividad media global de un área bioproductiva, en relación con la productividad media global de todas las áreas bioproductivas, se obtiene un valor final de 56,48 millones de hectáreas anuales, para el total de las emisiones de $\mathrm{CO}_{2}$ (un total para toda España de 294.118,4 miles de toneladas) emitidas por el sector del transporte por carretera en 2009.

\section{BIBLIOGRAFÍA}

DOMÉNECH, J.L. (2006) «Guía metodológica para el cálculo de la huella ecológica corporativa», Terceros encuentros internacionales sobre «desarrollo sostenible y población» eumed.net, Universidad de Málaga 
EMEP/EEA, (2009). «Air Pollutant Emission Inventory Guidebook». UNECEConventionon long-range transboundary air pollution \& European Environmental Agency.

ENVIRONMENTAL EUROPEAN AGENCY. (2009). Greenhouse gas emission trends and projections in Europe 2009. Copenhagen.

GARRÍAN, D. (2006). «La Huella Ecológica del transporte en las carreteras españolas». Congreso Nacional de Medio Ambiente.

GUÍA UNECE, (2003). Estimación y presentación de inventarios de emisiones «Guidelines for Estimating and Reporting Emission Data under the Convention on Long-range Transboundary Air Pollution. EC/EB.AIR/80-Air Pollution Studies No. 15». NECE, 2003.

Higón, F. (2010). Regulación de los impactos ambientales del sector del transporte por carretera: las emisiones de gases con efecto invernadero. XVII Encuentro de Economía Pública. Murcia.

INE (2009). «Anuario Estadístico de España» (2009).

INE (2010). Serie 1995-2009 de producto interior bruto (PIB) y valor añadido bruto (VAB) de agricultura, energía, industria, construcción y servicios.

«Inventarios Nacionales de Emisiones a la Atmósfera 1990-2006», (2008). Dirección General de Calidad y Evaluación Ambiental. Ministerio de Medio Ambiente, y Medio Rural y Marino.

Libro Guía EMEP/CORINE-AIR (2001). «Atmospheric Emission Inventory Guidebook». Third Edition. 2001, Updated to December 2007. UNECE-Convention on long-range transboundary air pollution $\&$ European Environmental Agency.

LENZ HP, PRÜLlER S, Gruden D. (2003). Means of Transportation and their effect on the environment. In: Gruden D (ed) The Handbook of Environmental Chemistry vol 3, Part T, Traffic and Environment. Springer Verlag: BerlinHeidelberg; 107-173 pp.

MANUAL CORINE-AIR (1992). «Default Emission Factors Handbook». Second Edition. Edited by CITEPA for DG-XI CEC.

MINISTERIO DE ECONOMÍA (2008). Informe de Recaudación Tributaria. Madrid

MINISTERIO DE FOMENTO (2008). Los transportes y los servicios postales. Madrid.

MINISTERIO DE INDUSTRIA, TURISMO Y COMERCIO (2010). «La Energía en España 2009». Madrid.

MINISTERIO DEL INTERIOR (2008). Anuario Estadístico General 2007. Madrid

MINISTERIO DE MEDIO AMBIENTE (2008). Inventario de emisiones de GEI de España. Años 1990-2006. Madrid.

MOPTMA. (1996) Método CORINE-AIRE para la elaboración del inventario nacional de gases de efecto invernadero y precursores de ozono. Madrid. 
Nieto, J. y SAntamarta, J. (2008). Las emisiones de gases de invernadero en España por comunidades autónomas. CCOO, Madrid.

Nieto, J. y Santamarta, J. (2009). Evolución de las Emisiones de Gases de Efecto Invernadero en España. CCOO, Madrid.

Pérez-Martínez PJ, Monzón de CÁCERES A. (2007). Transporte y medio ambiente en España: un análisis que exige un mayor control de la demanda. Estudios de Construcción y Transporte.

Pérez-Martínez PJ, Monzón de CÁCERes A. (2009). Relación entre las emisiones de GEI debidas al transporte por Comunidades Autónomas y la renta por habitante. Carreteras.

RICHARDSON, B. (2005). «Sustainable transport: analysis frameworks». Journal of Transport Geography.

Rodrigo, F. y SAntamarta, J. (2008). Evolución de las Emisiones de Gases de Efecto Invernadero en España (1990-2007). CCOO, Madrid.

SANTAMARTA, J. (2005). Las emisiones de gases de invernadero en España por comunidades autónomas, World Watch no 23, Madrid

Sotelo, J.A. (2000), Regional Development Models, Oxford University Press, 195 pp.

Sotelo, J.A. (2001). Environmental Europe, Londres, Oxford University Press.

Sotelo, J.A. (2001). Estudiar la Región, Madrid., INFODAL., 290 págs.

Sotelo, J.A. (2007). Medio Ambiente, Desarrollo y Sostenibilidad: Modelos y Políticas de actuación contradictorias: entre lo global y lo local, Oxford University Press.

TOlón, A. et alii (2011). «Propuesta metodológica de distribución territorial de la reducción de emisiones de $\mathrm{CO}_{2}$ en el sector del transporte de acuerdo con el Protocolo de Kyoto y la política energética de la Unión Europea». Prensa.

WACKernagel, M., ReEs, W. (1995) «Our Ecological Footprint: Reducing Human Impact on the Earth», New Society Publishers, Gabriola Island, BC \& Philadelphia, PA, USA.

Yabar Sterling, A. (2005). «Diseño del Post-Kioto. Opciones, principios, objetivos y políticas sobre el cambio climático en la UE, frente al segundo período de compromiso». Observatorio Medioambiental. 19pp

YABAR Sterling. A. (2010). «El esfuerzo español de mitigación de las emisiones de los «sectores no directiva» y su distribución entre las CCAA». Observatorio Medioambiental. $39 \mathrm{pp}$. 